\title{
Crystal-chemistry of interstratified Mg/Fe-clay minerals from seafloor hydrothermal sites
}

\author{
Javier Cuadros ${ }^{a, *}$, Joseph R. Michalski ${ }^{a}$, Vesselin Dekov ${ }^{b}$, Janice Bishop ${ }^{c}$, Saverio Fiore ${ }^{d}$, \\ M. Darby Dyar
}

\footnotetext{
${ }^{a}$ Department of Earth Sciences, The Natural History Museum, Cromwell Road, London SW7 5BD, UK

${ }^{\mathrm{b}}$ Laboratoire de Géochimie et Métallogénie, Département Géosciences Marines, IFREMER, Z.I. Pointe du diable, BP 70 - 29280 Plouzané, France

${ }^{c}$ SETI Institute, Mountain View, CA 94043, USA

d Institute of Methodologies for Environmental Analysis, CNR, Dept. of Geoenvironmental \& Earth Sciences, University of Bari, Via Orabona 4, Bari, Italy

e Mount Holyoke College, 50 College St., South Hadley, MA 01075, USA
}

\author{
*: Corresponding author : Javier Cuadros, tel.: + 442079425543 ; fax: + 442079425537 ; \\ email address : j.cuadros@nhm.ac.uk
}

\begin{abstract}
:
Seafloor hydrothermal sites generate abundant $\mathrm{Mg}$ - and Fe-rich clays. These clays are structurally and compositionally interesting because these environments are characterized by large, dynamic temperature and chemical gradients in their deposition environment, which promote the formation of chemically and structurally complex clays, including interstratified phases. The system is also interesting as a proxy for the study of the large $\mathrm{Mg}$ - and Fe-rich phyllosilicate deposits on Mars, which are broadly characterized as smectitic clay of hydrothermal, volcanic or sedimentary origin. Thirty submarine samples and four terrestrial ones, for comparison, were studied by means of X-ray diffraction (XRD), thermogravimetry (TG), mid-IR and Mössbauer spectroscopies and chemical analysis. The samples include nontronite and the mixed-layer phases glauconite-nontronite, talcnontronite and talc-saponite. Some of the talc-saponite samples have $\mathrm{Fe}$ contents well above those typical for these Mg-rich, trioctahedral phases (up to $1.69 \mathrm{Fe}$ per $\mathrm{O}_{10}[\mathrm{OH}]_{2}$, in the tetrahedral and octahedral sheets). Tetrahedral Fe ranges from 0 to 0.66 atoms per $\mathrm{O}_{10}[\mathrm{OH}]_{2}$ across the samples. As found in previous studies of similar specimens, Fe promotes the retention of molecular water that is released upon heating above $200 \mathrm{C}$, and is mainly emplaced in non-expandable layers (talc and glauconite layers). In talc-nontronite and talc-saponite octahedral Fe (both di- and trivalent) appears to be bound to this trapped molecular water, whereas in glauconite-nontronite the bond appears to be with tetrahedral Fe. Samples typically show more than one dehydroxylation event in the TG analysis. The weight loss at each dehydroxylation event is broadly consistent with the proportion of individual layers as determined by means of XRD, but there is no good correlation between both. By contrast, the weight loss at each dehydroxylation event correlates with the chemistry of the layers, where certain cations promote chemical domains in the octahedral sheet (e.g., trioctahedral, nontronite-like, montmorillonite-like, etc.) that dehydroxylate at the several temperatures. The correlations found for talc-nontronite and glauconite-nontronite samples suggest that the distribution of cations in the octahedral sheets of most, but not all, samples is intermediate between total dispersion and total segregation, perhaps random. The talc-nontronite samples have talc layers with cation-deficient octahedral sheets. The above results are best explained by layers of polar character, where the
\end{abstract}


octahedral sheets are composed of domains with different chemical characteristics corresponding to the two types of layers in the interstratified clay. The existence of molecular water (bands at 1635 and $3300-3500 \mathrm{~cm}^{-1}$, or $\sim 6.1$ and 2.9-3.1 $\mu \mathrm{m}$, respectively) bound in non-expanding layers is relevant to the mineral characterization of Martian Fe-rich clays with spectroscopic methods, where molecular water is so far assumed to be linked to smectite. The variety of mixed-layer clays in which $\mathrm{Fe}$ is found in the submarine samples suggests that mixed-layering may be important in Martian clays, which are spectroscopically variable but generally Fe-rich.

\section{Highlights}

Seafloor hydrothermal clays are mainly mixed-layer $\mathrm{Mg}$ - and Fe-rich phases $>$ Non-expandable clay layers trap molecular water near to structural Fe Water in Fe-, Mg-rich clay on Mars may not necessarily indicate smectite Octahedral sheets in clay layers have domains of different composition $>$ Clay layers are polar and do not correspond to mineral end-members

Keywords : Interstratified clays ; Martian clays ; Submarine hydrothermal sites ; Thermogravimetry ; XRD

\section{Introduction}

Interstratified clay minerals are an important group within the fine-grained phyllosilicates because (1) they are abundant, (2) they contribute information about unstable or changing environmental conditions, (3) they provide information about clay reaction mechanisms, and (4) they reveal crystalchemical stability fields (Cuadros et al., 2010; Cuadros 2010). Recent work has highlighted that interstratified clays have very complex crystal-chemistry (Cuadros, 2012), including hybrid kaolinitesmectite layers (Dudek et al., 2006; Cuadros et al., 2009), dioctahedral and trioctahedral layers (Cuadros et al., 2008; Aldega et al., 2009) and three types of layers in one mixed-layer phase, rather than only two as is more common (Drits et al., 1997). Submarine hydrothermal sites at spreading centres are great natural laboratories for the study of mixed-layer clays because steep temperature and chemical gradients are generated there by the mixture of hydrothermal fluids and seawater. The interaction of these fluids with basaltic rocks and metalliferous and biogenic sediments lead to the formation of a range of clay minerals such as talc, disordered talc (kerolite), saponite, nontronite, celadonite, glauconite, chlorite, 7- $\AA$ Mg-rich phases, sepiolite and palygorskite (Cole, 1985; Weaver, 1989; Chamley, 1989), as well as many of their interstratified phases such as chlorite-smectite, glauconite-nontronite and talc-smectite (Weaver, 1989; Chamley 1989; Buatier et al., 1995; Cuadros et al., 2008; Dekov et al., 2008a). In talc-smectite, the smectite is more frequently saponite, and thus both components are trioctahedral, but the smectite can also 
be montmorillonite, generating a system with di- and trioctahedral components (Cuadros et al., 2008). Thus, the study of clay phases from submarine hydrothermal sites is likely to shed further light on the crystal-chemistry of interstratified phases. Because clays in these environments are typically Mg-and/or Fe-rich, these materials will contribute information mainly, but not only, in the Si-Mg-Fe clay compositional field.

Submarine Mg- and Fe-rich clays are also relevant to understanding the environments and processes that produced the massive Mg- and Fe-rich clay deposits on Mars at the early stages of its evolution (Poulet et al., 2005; Bibring et al., 2006; Murchie et al., 2009; Ehlmann et al., 2011). The similar clay mineralogy and chemistry (within the Mg-Fe-Si system) points towards parallel elements that can be discovered by the careful investigation of the Earth analogues and comparison with data from Mars. Presently, our knowledge of Martian clays is based on IR spectroscopic data that provide information about their water content, some structural elements, and rough chemical composition (Poulet et al., 2005; Bibring et al., 2006; Murchie et al., 2009; Ehlmann et al., 2011). The mineralogical characterization may be more problematic because the shape of spectral features depends not only on mineralogy but also on crystal order, chemical substitution and mixed-layering. It is, then, important to have full information of Fe- and Mg-rich clays occurring together on Earth in order to validate and further our knowledge of the Martian counterparts. Are they separated phases? Do they have substantial Mg-Fe substitution? If so, is it accommodated in interstratified phases or homogenously within every layer?

In this contribution, we present a crystal-chemical investigation of Fe- and Mg-rich clays from several submarine hydrothermal sites around the world (although mainly from the Red Sea) covering the compositional range talc—saponite-nontronite-glauconite. The great majority of them are interstratified phases rather than end-members. The results further our knowledge of the nature of the layers and the location of cation substitution in these mixed-layer clays. Comparison with Mars data will be carried out in subsequent contributions.

\section{Materials and methods}




\subsection{Sample origin}

The samples were obtained from several collections and comprise specimens from seafloor hydrothermal fields from the Atlantis II Deep (Red Sea), Guaymas Basin (Gulf of California), Grimsey Graben (Tjörnes Fracture Zone; off the Icelandic north coast), East Pacific Rise, and Mid-Atlantic Ridge (Table 1).

The Atlantis II Deep is a tectonic depression within the actively spreading Red Sea rift, which is filled with stratified, hot, saline brine. The brine layers are a dynamic system with temporal changes in temperature and dissolved elements related to hydrothermal venting in the southwest basin of the Deep (Zierenberg and Shanks, 1983). The Atlantis II Deep seafloor is covered by a complex metalliferous sediment layer composed of silicates, sulfides, sulfates and oxyhydroxides (Zierenberg and Shanks, 1988). The calculated maximum temperature of hydrothermal fluids is 390 C (Zierenberg and Shanks, 1988). We studied a sample set from the South-West and West Basins.

Guaymas Basin is part of the rift zone in the Gulf of California that contains two overlapping troughs, termed Northern and Southern. Both troughs are floored by thick turbidite sediment. In the Northern Trough the thick sediment blanket is intruded by a series of sills and doming magma bodies (Lonsdale et al., 1980). A high-temperature (280 C) hydrothermal system has deposited terraces and ledges of talc and pyrrhotite (Lonsdale et al., 1980). The sample studied here was recovered from a small hill with a flat summit.

The Grimsey hydrothermal field lies in the Grimsey Graben ( 30 km north of Iceland and east of the Grimsey Island), a sediment-filled pull-apart basin within the Tjörnes Fracture Zone (TFZ). TFZ is a spreading axis offset, which links the north Iceland rift zone with the southern Kolbeinsey Ridge (Rögnvaldsson et al., 1998). The shallow-water ( 400 m) hydrothermal field crowns two mound structures and comprises about 20 anhydrite mounds and chimneys jetting hightemperature (250 C), clear, metal-depleted hydrothermal fluids (Hannington et al., 2001). Shimmering water, boiling hydrothermal springs (submersible observations) and hot (up to $102 \mathrm{C}$ ) 
sediments cored in the central part of the field, indicate that the entire area is thermally active and underlain by a large boiling zone (Hannington et al., 2001; Dekov et al., 2008b).

We investigated also samples from the hydrothermal fields of two seamounts located close to the crest of the East Pacific Rise: Red Seamount and Southeastern Seamount. The Red Seamount is a tholeiitic off-axial seamount situated at $21^{\circ} \mathrm{N}$ East Pacific Rise (Alt et al., 1987). It is presently hydrothermally active. Deposits consisting mostly of Fe-oxyhydroxides are forming at temperatures of $\sim 15 \mathrm{C}$, whereas nontronite and Mn-oxides form at temperatures of $\sim 30 \mathrm{C}$ (Alt et al., 1987). A hydrothermal deposit was sampled on the southern summit bench of the seamount. Southeastern Seamount is located $\sim 6 \mathrm{~km}$ to the east of the East Pacific Rise axis at $13^{\circ} \mathrm{N}$ (Hekinian and Fouquet, 1985). No recent volcanic and hydrothermal activity was observed on it, but an extensive inactive hydrothermal field composed of sulfides and oxyhydroxides was found and sampled at the summit of the seamount (Hekinian and Fouquet, 1985). Inferred temperature of deposition is up to $\sim 200$ C.

The Turtle Pits hydrothermal field is located at $\sim 5^{\circ} \mathrm{S}$ on the Mid-Atlantic Ridge. It is composed of a large active black smoker chimney and two mounds of sulfide debris capped by numerous small active black smokers (Haase et al., 2007). Vigorously venting fluids have temperatures of $407 \mathrm{C}$, which is the seawater boiling point at the depth of the field. In addition to the sulfide assemblage, primary hydrothermal hematite-magnetite-pyrite association is described in the inactive mounds and chimneys (Haase et al., 2007).

The Logatchev hydrothermal fields are located at $\sim 14^{\circ} 45^{\prime} \mathrm{N}$ of Mid-Atlantic Ridge (Petersen et al., 2009). They lie at the eastern inner flank of the rift valley wall and comprise two active hydrothermal fields, Logatchev- 1 and -2 , each of them having several active and inactive vent sites. The hydrothermal activity at both fields is structurally controlled and localized in debris flows consisting of heterogeneous ultramafic and mafic intrusive rock clasts (Petersen et al., 2009). Basaltic volcanism and associated gabbroic intrusions beneath the eastern flank of the rift valley are inferred to be the heat source driving the hydrothermal circulation at Logatchev (Petersen et 
al., 2009). The venting occurs mainly in so-called smoking craters and is related to small, fragile sulfide chimneys at the crater rim or occurs directly from holes in the crater floor without chimney formation (Petersen et al., 2009).

The studied samples were selected from a larger set based upon their clay content and the nature of the other mineral phases, considering whether these phases could be removed or, if not, the extent of the likely interference with the study of the clays. For example, specimens with high $\mathrm{Fe}$ oxide content were generally avoided, as well as samples with significant contamination of phases containing $\mathrm{Mg}$ and $\mathrm{Si}$. We also studied four terrestrial samples of mineralogical and chemical characteristics similar to those found in the submarine samples, in order to investigate whether their crystal-chemistry is comparable. The terrestrial samples are a glauconite of lacustrinepedogenic origin from the Isle of Wight, Nontronite 33B from Washington, generated by hydrothermal alteration of basalt, Nontronite 51 (actually containing nontronite and talc) from unknown origin and location, and CRB-03-026, a mixture of celadonite and saponite from Washington, formed by hydrothermal alteration of the upper part of the Imnaha Formation. Further information about sample localities, description and literature references are provided in Table 1. Within specific cores, the sample identity is provided by the last two figures in the label, that indicates the depth $(\mathrm{cm})$ in the core.

\subsection{Sample preparation}

Analyses were carried out at The Natural History Museum, London, unless stated otherwise. Some samples were dry and consisted of loose sediment. Those collected recently from the original cores were wet and were therefore dried in an oven at $40 \mathrm{C}$. After drying, many samples had large halite and gypsum crystals, which were removed by hand. Sample Sea Cliff Dive 308 consisted of red and light-colored material and only the latter was used in the study (the word "light" was added to the label). The red-stained part of the sample (see description in Table 1) was discarded because it contained mainly Fe oxides. The sediments were ground with pestle and mortar to homogeneous powders. After X-ray diffraction (XRD) analysis of these powders (see below), it was decided whether they needed further purification. Three purification processes were 
used. Those containing halite or gypsum were repeatedly washed using deionized water. Suspensions of the sediment (sediment/water volume ratios of $1 / 3$ or less) were allowed to react for 1 day and frequently stirred. Then they were separated by centrifugation (12,000 rpm or $18,527 \times g)$, and the process was repeated. Sediments containing insoluble coarse-grained phases (e.g., barite, feldspar) were purified by particle size separation $(<2$ or $4 \mu \mathrm{m})$ in deionized water suspensions by centrifugation.

Sediments containing amorphous or crystalline Fe oxides, as detected by XRD or obvious by the red color of the sediment, were treated with the dithionite-citrate-bicarbonate method for $\mathrm{Fe}$ extraction of Mehra and Jackson (1960). This method allows dissolution of poorly crystalline $\mathrm{FeOOH}$ phases as well as goethite, lepidocrocite, hematite and ferrihydrite (Parfitt and Childs, 1988). The method was applied repeatedly until the sediments lost their red color, that was typically substituted by a deep grey. A few samples were difficult to sediment entirely in the centrifugation process after each extraction, even using water-acetone mixtures consisting mainly of acetone. This behavior created problems in eliminating the supernatant, which contained dissolved species from the extraction process, and thus produced sample contamination. The samples were finally washed repeatedly with deionized water first and then with water-acetone mixtures, by centrifugation. After the purification processes, the samples were oven-dried (40 C) and ground to a powder.

\subsection{Scanning electron microscopy (SEM)}

The original sediments were studied with SEM-EDX to investigate further their mineralogy and composition, and to confirm our interpretation of contaminants. The sediments consisted of loose powder or chips. Chips were glued to Al stubs, taking care of exposing a horizontal face at the top, and a minimum of silver colloidal suspension was added to the contact between chip and stub. Powders were prepared by depositing a very thin layer of glue on the stub, pressing the stub gently on the powders and tapping it to eliminate grains that were not firmly glued. The samples were then C-coated. They were investigated in a LEO 1455 VP and Carl Zeiss Ultra Plus Field Emission microscopes, both equipped with EDX Oxford Instruments X-Max detectors. Imaging was carried 
out using both back-scattered and secondary electrons. The typical collection time for EDX analyses was $50 \mathrm{~s}$. No SEM results are presented here but we refer to SEM investigation in the identification of contaminants.

\subsection{XRD}

The ground sediments were analysed for their bulk mineralogy, previous to sample purification, using a PANalytical X'Pert Pro diffractometer, at $45 \mathrm{kV}$ and $40 \mathrm{~mA}$, using Cu Ka radiation, with divergence slit of $0.25^{\circ}$, and Soller 1 and 2 slits of $1.146^{\circ}$. This apparatus uses a solid-state detector ( $X^{\prime}$ Celerator) covering an angle of $2.1^{\circ}$ and integrates the diffracted intensity over that angle dynamically as it scans. The powders were scanned in the range $2-80^{\circ} 2 \theta$, with a resolution of $0.0167^{\circ} 2 \theta$ (scan step in a conventional scanner), and the total collection time was 60 min (equivalent to $0.77 \mathrm{~s} / \mathrm{step}$ ). To avoid preferential orientation of the clay particles, the samples were side-loaded. The same side-loaded samples were also scanned at low speed (62 min scan,

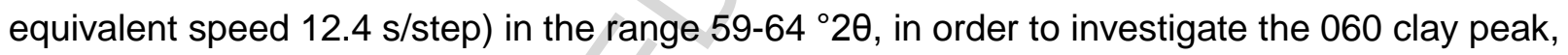
with all other conditions as above.

The detailed investigation of the clay composition was carried out on the samples after elimination or minimization of non-clay phases (see above). The purified samples were prepared as oriented mounts by dispersing $10 \mathrm{mg}$ of them in $2 \mathrm{ml}$ of deionized water, pipetting the dispersion on glass slides (area of $\sim 4 \mathrm{~cm}^{2}$ ), and letting them dry. They were studied as air-dry and as treated with ethylene-glycol (EG) by overnight contact with an EG-saturated atmosphere at $60 \mathrm{C}$. The scan range was $2-40^{\circ} 2 \theta$, scanned in $63 \mathrm{~min}$ (equivalent to $1.66 \mathrm{~s} / \mathrm{step}$ ). All other conditions were as above. The quantification of the interstratified clay phases was carried out by modeling the patterns after EG treatment using CLAYSim from MDI. This software allows modeling of the 00I peaks of interstratified minerals with two layer components, and mixtures of up to ten such phases. The EG patterns were used because glycolated smectite layers expand more uniformly than in air-dry systems and the results are more accurate. The experimental conditions of the scans were used in the program calculations. Some of the samples had low crystallinity (only a wide 001 peak was discernible). Their nature was assessed using both the XRD modelling and a quantification of the 
two clay types using the 060 peaks. For the quantification of the 060 peak components, the XRD trace was fitted to Gaussian peaks and their areas were measured, using GRAMS/AI software from Thermo Galactic.

\subsection{Infrared spectroscopy}

Clay samples were analysed by mid-infrared transmission spectroscopy. All spectral analyses were carried out on clay samples after any necessary size separations, washing, and/or chemical treatment was carried out. Spectra were collected using a Perkin Elmer Spectrum One FTIR spectrometer. Two mg of each powdered clay sample were combined with $\sim 198 \mathrm{mg}$ of $\mathrm{KBr}$ and gently ground to produce a homogeneously mixed clay-KBr powder and subsequently pressed at $10 \mathrm{~T}$ for one minute to produce a $\mathrm{KBr}$ pellet with $\sim 1 \%$ clay. Infrared transmission spectra were recorded over the spectral range $200-4000 \mathrm{~cm}^{-1}$ at a spectral resolution of $4 \mathrm{~cm}^{-1}$. Eight spectra were accumulated for each sample. The humidity levels were not controlled, but the effect of water vapor on spectra was monitored continuously and any samples showing problematic signs of adsorbed water were prepared again and re-analyzed.

\subsection{Thermogravimetry and evolved gas analysis}

Thermogravimectric (TG) analysis was performed at the University of Bari using a Seiko XSTAR 6000 on the powder samples after the chemical and/or physical separation of other mineral phases. The samples were heated in alumina crucibles from 20 to $1100 \mathrm{C}$ at $10 \mathrm{C} / \mathrm{min}$ in a nitrogen flow. Sample weight range was $4-20 \mathrm{mg}$, typically $<10 \mathrm{mg}$. Some of the TG diagrams were complex and indicated reactions affecting several mineral phases. To help identifying the reactions corresponding to clay minerals, evolved gases from some of the samples were analysed using IR spectroscopy. These samples were analysed a second time for the evolved gas (EGA), connecting the furnace of the TG apparatus to a FTIR spectrometer Thermo Nicolet 5700 equipped with a Thermo TGA-FTIR interface. The interface was heated at $200 \mathrm{C}$ to avoid gas condensation and a flow of ultrapure nitrogen of $60 \mathrm{ml} / \mathrm{min}$ carried the evolved gases to the FTIR spectrometer. Analysis conditions were similar to those above except that they were heated at $20 \mathrm{C} / \mathrm{min}$. Four gases were found to evolve, $\mathrm{H}_{2} \mathrm{O}, \mathrm{CO}_{2}, \mathrm{SO}_{3}$ and $\mathrm{SO}_{2}$. To identify the evolution patterns of each 
gas during the experiment, the composite spectra at each collected interval were investigated for absorption at the following wavenumbers, which are specific for each of the gas of interest, 1350 $\mathrm{cm}^{-1}\left(\mathrm{SO}_{2}\right), 1380 \mathrm{~cm}^{-1}\left(\mathrm{SO}_{3}\right), 1550 \mathrm{~cm}^{-1}\left(\mathrm{H}_{2} \mathrm{O}\right)$, and $2350 \mathrm{~cm}^{-1}\left(\mathrm{CO}_{2}\right)$. Then the IR absorption at each of the above wavelengths was plotted versus the temperature of analysis, producing the profile of the gas evolution during the experiment.

\subsection{Mössbauer spectroscopy}

Twenty one out of the 30 submarine specimens were studied with Mössbauer spectroscopy at Mount Holyoke College, Massachussetts. No sample was available of the 7 specimens from Grimsey Graben at this stage, and the other two samples had low Fe contents (Logatchev and Va1-52KH-323-327). Sample mounts were prepared by gently mixing 30-40 mg of powdered sample with sugar to reduce preferred orientation. To mitigate the effects of thickness, we ran all our samples at $<2 \mathrm{mg} \mathrm{Fe} / \mathrm{cm}^{2}$, well below (an order of magnitude less than) the "ideal" thicknesses calculated by Long et al. (1983); discussion of this effect is given in Dyar et al. (2008). The mixtures were placed in a sample holder confined by Kapton tape. Mössbauer spectra were acquired at $295 \mathrm{~K}$ using a source of $\sim 40 \mathrm{mCi}{ }^{57} \mathrm{Co}$ in $\mathrm{Rh}$ on a WEB Research Co. model WT302 spectrometer. For each sample, the fraction of the baseline due to the Compton scattering of 122 keV gammas by electrons inside the detector was determined by measuring the count rate with and without a 14.4-keV stop filter ( $2 \mathrm{~mm}$ of $\mathrm{Al}$ foil) in the gamma beam. Compton-corrected absorption was calculated for each individual spectrum using the formulation $A /(1-b)$, where $b$ is the Compton fraction and $A$ is the uncorrected absorption. This correction does not change the results of the fits per se but does allow accurate determination of \% absorption in the spectra. The correction is necessary because the range of energy deposited in the detector by Compton events extends from 0 to $40 \mathrm{keV}$, overlapping both the $14 \mathrm{keV}$ and $2 \mathrm{keV}$ energies deposited by the 14 keV gammas.

Run times were 6-48 $\mathrm{h}$ for each spectrum, and baseline counts were $\sim 3-15$ million after the Compton correction, as needed to obtain reasonable signal-to-noise ratios. Data were collected in 1024 channels and corrected for nonlinearity via interpolation to a linear velocity scale, which is 
defined by the spectrum of the $25 \mu \mathrm{m}$ Fe foil used for calibration. Data were then folded before fitting, using a procedure that folds the spectrum about the channel value that produces the minimum least squares sum difference between the first half of the spectrum and the reflected second half of the spectrum. All Mössbauer data are posted for public use at http://www.mtholyoke.edu/courses/mdyar/database/.

Spectra were fit with two or three Lorentzian doublets using the MEX_FieIDD program acquired from the University of Ghent, courtesy of E. DeGrave. Isomer shifts (IS, or $\delta$ ), and quadrupole splittings (QS, or $\Delta$ ) of the doublets were allowed to vary, and widths (full width at half maximum) of all four peaks were coupled to vary in pairs. In a few cases, it was necessary to constrain peak widths to lie above a certain value to obtain reasonable parameters, but most spectra were fit with only the minimal constraints described above.

Error bars for Mössbauer measurements are discussed at length by Dyar (1984) and Dyar et al. (2008), with fits to well-resolved spectra giving errors of $\pm 0.02 \mathrm{~mm} / \mathrm{s}$ for IS and QS, and $\pm 3 \%$ absolute on areas. In many of the spectra studied here, there are multiple overlapping distributions, so the errors are likely slightly higher: $\pm 0.02-0.05 \mathrm{~mm} / \mathrm{s}$ for IS and QS, with errors of $\pm 3-5 \%$ absolute on areas. Reproducibility (precision) of peak areas based on repeated fits using different constraints $(\delta, \Delta$, width, and areas constrained in all possible combinations of individual peaks and pairs) and fitting models (Lorentzian, Gaussian, quadrupole splitting distributions) is $\pm 0.3 \%$ absolute for these well-resolved spectra. Accuracy has been determined in previous studies of amphiboles to be $\pm 3-5 \%$ (Dyar, 1989) but is highly dependent on the spectrum being analyzed; a lengthy discussion of this issue is given in Dyar et al. (2008).

\subsection{Chemical analysis}

Chemical analysis was performed on the samples after chemical and physical treatment to eliminate or reduce other mineral phases. The powders were dissolved by acid attack with HF$\mathrm{HClO}_{4}$-aqua regia in closed bottles in a microwave oven (Thompson and Walsh, 2003) with or without previous fusion with $\mathrm{LiBO}_{2}$. The solutions were analyzed using inductively coupled plasma- 
atomic emission spectrometry (ICP-AES, in a Thermo iCap 6500 Duo). Results are reported relative to dry weight (110 C overnight). Analytical errors were 1-7\% weight relative to the element oxide results for major elements (average of $4 \%$ ), and 2-17\% weight of elements for traces (average of $7 \%$ ), also relative to the determined values. The chemical analyses were corrected for non-clay mineral phases that had not been removed in the original treatment and then converted to structural formulas on the basis of $\mathrm{O}_{10}(\mathrm{OH})_{2}$. The proportion of $\mathrm{Fe}^{2+}$ was taken from Mössbauer spectroscopy. Mössbauer and IR spectroscopy were used as guides for allocation of $\mathrm{Fe}$ and $\mathrm{Al}$ between the tetrahedral and octahedral sheets. Magnesium was allocated to the octahedral sheet unless in evident excess (two samples), in which case some was allocated to the interlayer. The difference between layer charge and interlayer cation charge was $0.0015\left(\right.$ per $\left.\mathrm{O}_{10}[\mathrm{OH}]_{2}\right)$ in one case and $<0.0008$ in the rest.

\section{Results}

\subsection{XRD}

The XRD patterns of the random powders (not shown) are frequently dominated by halite and gypsum peaks, with broad or low-intensity clay peaks that suggested low crystallinity. There were exceptions where the samples were almost entirely clay and/or where the clay peaks were intense. Other phases found were, from more to less abundant, hematite, goethite, huntite, pyrite, birnessite- $\delta \mathrm{MnO}$ and other $7-\AA \AA \AA$ phases, jarosite, mirabilite, olivine, pyroxene and plagioclase. The 7-Å phases can consist of Mg- or Fe-rich clay and/or hydrotalcite (see TG-EGA evidence below from low-temperature $\mathrm{CO}_{2}$ loss). Samples were treated according to these results to eliminate contaminant phases (methods section). We did not observe any signs of amorphous silicate material in any of the submarine samples, consistent with the fact that they are not in-situ altered basalt but sediments generated via several other routes.

The XRD patterns of the oriented samples, air-dry and glycolated, showed that they consisted of interstratified talc-saponite (T-S), talc-nontronite (T-N), glauconite-nontronite $(\mathrm{G}-\mathrm{N})$, and a few nontronite end-members. The nature (saponite or nontronite) of the smectite component in the mixed-layer clays was corroborated using the chemical analysis and IR spectroscopy. Many of the 
samples displayed complex XRD patterns that were modeled (traces from EG treatment only) using 2-4 phases of interstratified or end-member minerals (Table 2). Examples of each one of the above groups (nontronite, G-N, T-N and T-S) are shown in Fig. 1. In the second pattern from the top, the 001 peak of the calculated pattern is displaced to a lower angle due to the combined effect of the low intensity of the peak and the steep background. It is known that the used program produces a steeper background than the experimental one in the low-angle region for a large variety of calculations (Plançon, 2002), as can be observed in Fig. 1. However, the calculation relies on the position of all 001 peaks. In most cases, the XRD patterns were consistent with random order of the interstratified layers $(R=0$, Table 2$)$ but there were patterns that showed evident signs of non-random order $(R>0)$.

Iron content has an effect on the XRD patterns. Our calculations showed that high Fe contents were necessary in most of the samples. There is however a relatively large error in the assessment of Fe content using this modeling, especially if the peak intensity is low, as in many of our samples. Iron was placed in the octahedral sheet of the modelled clays, whereas chemical analysis and Mössbauer spectroscopy revealed that there is also tetrahedral Fe. For the above reasons, it can only be expected that the XRD models produce a rough assessment of Fe content.

The investigation of the 060 peaks (Fig. 2) corroborated the nature of the samples as indicated by the other techniques. Samples in the groups T-S and G-N typically displayed only one peak, at a dspacing consistent with tri- and dioctahedral clay, respectively. Nontronite samples displayed one 060 peak. T-N samples displayed two peaks of varying relative intensity, consistent with the presence of a dioctaheral and a trioctahedral phase. The following specimens are T-N of low crystallinity: Va22-146KS-471-475, -575-577, -583-586, -602-603, and CHN-100-18PC-290-292. For these samples, the relative proportion of talc and nontronite was first assessed from the relative areas of the corresponding 060 XRD peaks (Fig. 2; see peak positions in Table 2). The obtained relative proportion of talc and nontronite was used to model a T-N phase with these corresponding proportions, for the glycolated mount. In all cases but one the model fit the experimental patterns. The exception was Va22-146KS-602-603, for which the model indicated 
$60 \%$ nontronite, whereas the assessment of 060 peaks indicated $50 \%$ nontronite (Table 2). The errors (expressed as value \pm error) in the relative proportion of smectite (nontronite or saponite) for most samples were calculated as Error = number of phases $\times$ estimated error per phase $/ 2$. The estimated error per individual phase depended on crystallinity and varied between 2 and 15\% (or \pm 1 and $\pm 7.5 \%$ ). For the $\mathrm{T}-\mathrm{N}$ samples the estimated error was $10 \%$ (or $\pm 5 \%$ ).

Other values in Table 2 assess the size of the coherent scattering domain in the $\mathrm{c}^{*}$ direction given by $N_{\max }$ and $N_{\text {ave }}$, and the degree of orientation of the mounts, $\sigma^{*}$. The size of the coherent scattering domain is defined as a range of layers from 1 to $\mathrm{N}_{\max }$ and the average number of layers $\mathrm{N}_{\text {ave }}$ (Moore and Reynolds, 1997). The degree of orientation, $\sigma^{*}$, is the standard deviation from perfect orientation expressed as a Gaussian distribution of the orientation of the clay plates. Values typically range from 12 , for a very good orientation, to 40 for a poor orientation (Moore and Reynolds, 1997).

The G-N samples cover a range of nontronite content from 23 to $68 \%$, whereas the $\mathrm{T}-\mathrm{N}$ are predominantly smectitic (60-80\% nontronite) and the T-S cover the entire range of composition (90-2\% saponite), although most of them are in the talc-rich end (2-27\% saponite). The seven samples from Grimsey Graben are all talc-rich T-S. Many samples are rather heterogeneous, containing phases with very different smectite and glauconite or talc content, which suggests formation conditions (chemistry and temperature) that varied within the $\mathrm{cm}$ scale or changed rapidly. Ordering $(R>0)$ of the interstratified layers in $\mathrm{G}-\mathrm{N}$ occurs when the proportion of nontronite in the individual phase is $\leq 20 \%$. On the contrary, the few cases of $\mathrm{R}>0$ in $\mathrm{T}-\mathrm{N}$ and T-S have no relation to the proportion of smectite in the corresponding individual interstratified phase.

\subsection{IR spectroscopy}

The mid-IR spectra corroborate the character of the samples as described by XRD and that their octahedral composition is dominated by Fe and Mg. However, although the major features in the spectra are consistent with $\mathrm{XRD}$ and chemical data, some of the minor features are apparently not and will require a more detailed analysis than is presented here. Figure 3 shows two sections of 
the IR spectra with relevant information for the characterization of the samples for four examples, one of each of the mineralogical groups found (T-S, T-N, G-N, and nontronite). Spectra of samples in the T-N, G-N and nontronite groups have dioctahedral bands dominating the $\mathrm{OH}$-stretching region (left panel, maxima at $3530-3640 \mathrm{~cm}^{-1}$ ). These bands have the typical shape of nontronite (wide bands with main maxima below $3600 \mathrm{~cm}^{-1}$; Russell and Fraser, 1994; Bishop et al., 2002) for T-N and nontronite, and that of glauconite (sharper bands, characteristic maxima at 3530, 3550 and $3635 \mathrm{~cm}^{-1}$; Russell and Fraser, 1994) for the G-N samples. The absence of a talc band in the T-N Va3-413KH-150-153 may be due to the low talc content in this sample (20\%) because talc bands were observable in other T-N samples with greater talc content. However, structural reasons such as poor crystallinity of the talc layers may also be the cause of the absence of the corresponding band in this sample. The spectrum of the T-S sample (Sea Cliff Dive) displays the typical $\mathrm{Mg}_{3} \mathrm{OH}$ band of talc at $3677 \mathrm{~cm}^{-1}$, plus two additional bands at 3661 and $3644 \mathrm{~cm}^{-1}$, caused by the substitution of Fe for Mg in the octahedral sheet, as described in other Fe-rich talc and T-S from similar settings (Cuadros et al., 2008). Spectra of other T-S samples displayed singlets, doublets or triplets for the $\mathrm{OH}$ stretching vibration, in good correlation with their octahedral Fe content.

Molecular water adsorbed on the clay surface and the interlayer produces multiple and wide $\mathrm{OH}$ stretching bands in the region $3600-3400 \mathrm{~cm}^{-1}(2.82-2.90 \mu \mathrm{m}$; partially shown in Fig. 3$)$ due to the range of environments, such as water coordinating interlayer cations, surrounded by other water molecules, bound to the clay O atoms, etc. (Bishop et al., 1994). The corresponding OH bending bands appear at $\sim 1650 \mathrm{~cm}^{-1}(\sim 6.06 \mu \mathrm{m}$; Fig. 3).

The right panel of Figure 3 shows the transition from the trioctahedral (top spectrum) to dioctahedral character (bottom spectrum) of the samples. The T-S sample (Sea Cliff Dive) displays a Si-O bending and lattice vibration system $\left(300-600 \mathrm{~cm}^{-1}\right)$ intermediate between those of talc and saponite (Russell and Fraser, 1994), and a large $\mathrm{OH}$-bending $\mathrm{Mg}_{3} \mathrm{OH}$ band at $668 \mathrm{~cm}^{-1}$, also with a shape intermediate between those of talc and saponite. The G-N and nontronite samples (bottom) have $\mathrm{OH}$ bending bands typical of Fe-dominated dioctahedral clays (main maxima at $815-819 \mathrm{~cm}^{-}$ 
${ }^{1}$, corresponding to $\mathrm{Fe}_{2} \mathrm{OH}$ ), a typical galuconite and nontronite band at $683 \mathrm{~cm}^{-1}$ of not totally defined origin (Fe-O out-of-plane: Russell and Fraser, 1994; Fialips et al., 2002; Gates, 2008; SiO[-Fe?]: Decarreau et al., 1992; Grauby et al., 1994; Neumann et al., 2011), and a band system below $600 \mathrm{~cm}^{-1}$ consistent with the nontronitic and G-N nature of the samples (Russell and Fraser, 1994; Bishop et al., 2002). The spectrum of T-N sample Va3-413KH-150-153 has several features that are intermediate between trioctahedral and Fe-rich, dioctahedral clays and some others that appear to be different from those in both groups. There is a low $\mathrm{Fe}_{2} \mathrm{OH}$ band at $820 \mathrm{~cm}^{-1}$, as in the G-N and nontronite samples. There is a band at $\sim 671 \mathrm{~cm}^{-1}$, with two unresolved maxima and intermediate between the nontronitic $\left(683 \mathrm{~cm}^{-1}\right)$ and trioctahedral $\left(668 \mathrm{~cm}^{-1}\right)$ bands described above, which is possibly resulting from their overlapping. These features are consistent with the T$\mathrm{N}$ nature of the sample. However, the band system centered at $447 \mathrm{~cm}^{-1}$ is featureless and unlike either the Fe-rich dioctahedral clays or the trioctahedral clays. A shoulder at $\sim 490 \mathrm{~cm}^{-1}$ could correspond to the G-N and nontronite band in this position. In this respect, sample Va3-413KH150-153 is not representative of the T-N group because the other samples did display a doublet in the $430-490 \mathrm{~cm}^{-1}$ region and the bands at $\sim 380$ and $\sim 340 \mathrm{~cm}^{-1}$ found in glauconite and nontronite. Apparently, this part of the spectrum of sample Va3-413KH-150-153 is affected by structural disorder that blurs the spectral features. It is also possible, but less likely in our opinion, that the contaminant phases described in the following section interfere with the IR signal in this part of the spectrum.

\subsection{TG and EGA analyses}

TG analysis documents four types of events in the clay minerals, which appear as weight loss in the TG diagram and peaks in the derivative of the TG line or DTG diagram (Fig. 4). In the range 25-100 C, there is loss of hydration water, mainly present in smectite. Between 200 and $300 \mathrm{C}$, there is water loss that has been described previously in this type of samples and assigned to water trapped within the hexagonal cavity in non-expanding layers (i.e., talc layers), associated with octahedral Fe (Cuadros et al., 2008). This water contributes to the molecular water IR vibrations described above (Cuadros et al., 2008). Also in the same range of temperature (200-300 C), some samples experienced weight loss due to organic matter combustion. This reaction was 
proven in the case of samples from Grimsey Graben (north of Iceland) because the weight loss correlated very well $\left(\mathrm{R}^{2}=0.9\right)$ with the area beneath the $\mathrm{C}-\mathrm{H}$ stretching region in their IR spectra $\left(2820-3030 \mathrm{~cm}^{-1}\right)$. The dehydroxylation temperatures range from 300 to $900 \mathrm{C}$, and are mainly in the range 300-500 for nontronite and G-N samples, and 600-900 C for T-S. Talc-nontronite has dehydroxylation events in both temperature ranges. Many samples had non-clay contaminants that complicated the interpretation of the TG/DTG diagrams. One example is sample Va3-413KH-150153 (Fig. 4). In this and similar cases, the interpretation of the diagram was carried out with the help of EGA analysis, which produced profiles of gas evolution during the experiments (not shown). The clay-related events in sample Va3-413KH-150-153 are the loss of hydration water below $200 \mathrm{C}$, and dehydroxylation at 300-400 C and at 600-700 C (arrows in Fig. 4). The other peaks are caused by pyrite $\left(\mathrm{SO}_{2}\right.$ and $\mathrm{SO}_{3}$ loss at $\sim 500$ and 800-900 C) and some other phase(s) that could not be identified (peaks at $200-400 \mathrm{C}, \mathrm{CO}_{2}$ loss in all thermal events). It is possible that the unrecognized phase is very disordered hydrotalcite, not detectable with $\mathrm{XRD}$, containing water, carbonate and sulphate ions, and producing gas evolution from $200 \mathrm{C}$ (Kloprogge et al., 2003).

Even if the TG/DTG diagrams of the analyzed samples did not show any evident sign of contamination, the dehydroxylation loss (after correction for hydration water) was typically above the theoretical value of $\sim 5 \%$ of the sample weight (average $6.1 \%$ ), suggesting the presence of contaminant phases producing significant gas evolution (within the dehydroxylation temperature range). In a few cases, however, the dehydroxylation loss was below $~ 5 \%$ (average 3.7\%), suggesting contaminant phases that produce very little or no gas evolution. Ten of the samples had a dehydroxylation loss within $4.5-5.5 \%$ of the sample weight.

For $\mathrm{T}-\mathrm{N}$, it is expected that there are at least two dehydroxylation events, one for nontronite layers (300-500 C) and one for talc layers (>600 C). Frequently, the other samples also showed more than one dehydroxylation event, the main one at the expected temperature according with the nature of the sample, and some other(s) small event(s) outside the expected range (e.g., thermal events at $\sim 502$ and $\sim 659 \mathrm{C}$ in the bottom diagrams of Fig. 4). If no contaminating phase responsible for the several thermal events was recognized, it was assumed that they corresponded 
to clay dehydroxylation, and they were interpreted to be caused by heterogeneous chemical domains within the octahedral sheet. The fact that not all the weight loss seems to be produced by clay dehydroxylation does not necessarily invalidate this assumption. If the contaminant phase releases gas (1) at the same temperature range of the major dehydroxylation event or (2) in a constant manner during a large temperature interval that is not reflected in the DTG diagram, the small thermal events would indeed correspond to clay dehydroxylation. This assumption was explored and provided insightful results as shown in the discussion.

\subsection{Mössbauer spectroscopy}

Results from Mössbauer spectroscopy allowed us to establish the relative proportion of $\mathrm{Fe}^{2+} / \mathrm{Fe}^{3+}$ in our samples, the amount of tetrahedral $\mathrm{Fe}^{3+}$, and the presence of magnetite in two samples, the one from Turtle Pits, where $70 \%$ of Fe was in magnetite, and Va3-413KH-313-318, where $21 \%$ of the Fe was in magnetite. The spectra typically showed more than one octahedral $\mathrm{Fe}^{3+}$ component. One tetrahedral $\mathrm{Fe}^{3+}$ component was common. One octahedral $\mathrm{Fe}^{+2}$ component was frequent in samples with non-expanding layers (i.e., T-S, T-N, G-N; Fig. 5, Table 3). Iron as Fe ${ }^{2+}$ readily oxidizes in expandable layers (smectite) when in contact with the atmosphere, while it is stable in non-expandable layers (thus found commonly and abundant in mica, chlorite, etc.). Individual clays frequently contain several octahedral Mössbauer Fe components, which are most probably caused by different octahedron distortions due to local structural and chemical differences (Drits et al., 1997). Iron from Fe oxide/hydroxide and clay phases cannot be distinguished in room-temperature experiments because the doublets overlap. However, sample Va3-413KH-382-389 contained significant hematite (XRD evidence) and we interpreted that one of the octahedrally coordinated

$\mathrm{Fe}^{3+}$ components corresponded to hematite (25\% of the $\mathrm{Fe}$ in the sample). Likewise, sample $1183-$ 9 contained goethite, so one of the octahedral $\mathrm{Fe}^{3+}$ components was assigned to it $(40 \%$ of total Fe). Iron in pyrite was not observable in the Mössbauer spectra due to low pyrite content.

\subsection{Chemistry}

The chemical analyses of the samples, showing all major elements and a few minor elements relevant for identification of mineral contamination $(\mathrm{S}, \mathrm{Zn}, \mathrm{Cu})$ are in Appendix A. This study seeks 
to obtain an accurate picture of the crystal-chemistry of the clay components and thus the chemical results had to be corrected for the presence of other mineral phases, most of which were in minor amounts. For the identification and quantification or assessment of the mineral contaminants, we used evidence gathered from XRD, TG, Mössbauer and IR spectroscopies and from the chemical analysis. Appendix B summarizes this information and indicates which type of pretreatment was carried out in each sample preparation. Typical contaminants were gypsum (in spite of the washing treatment), jarosite, pyrite and olivine, and less frequently Na-bicarbonate, carbonates and Fe oxides. Corrections for olivine and feldspars were carried out using end-member compositions according to the elements that appeared to be more in excess as a contaminant. Sodium bicarbonate was introduced during the pretreatment for $\mathrm{FeOOH}$ extraction because the solids could not be washed properly after the reaction (see Methods). Sample 1183-9 contained significant goethite after FeOOH extraction. Elevated $\mathrm{Zn}$ and $\mathrm{Cu}$ concentrations were indicative of the presence of sulphides and typically associated with pyrite detection by means of XRD. High Mn content indicated the presence of $\mathrm{MnOOH}$.

The chemical data after correction were transformed into structural formulas of $2: 1$ clays. The correction procedure for mineral contaminants was tested in the following manner. $\mathrm{Fe}^{3+} / \mathrm{Fe}^{2+}$ ratios were taken from Mössbauer spectroscopy and the formulas were calculated, assigning Al and the necessary $\mathrm{Fe}^{3+}$ to the tetrahedral sheet. Ferrous $\mathrm{Fe}$ is considered too large to populate tetrahedral sites, as corroborated by Geatches et al. (2012), who obtained results from ab initio calculations indicating that $\mathrm{Fe}^{2+}$ is not stable in tetrahedral positions. We then compared the proportion of tetrahedral and octahedral Fe from the formulas and from the Mössbauer data, which were coincident to $>90 \%$, thus corroborating the accuracy of the chemical corrections. We then refined the amount of tetrahedral Fe in our samples using the Mössbauer and IR data, where the latter provided evidence for octahedral Al in a few cases.

The final formulas (Table 4) have octahedral occupancies in good agreement with the nature of the samples as determined using the entire set of analytical techniques: dioctahedral in the case of G$\mathrm{N}$ and nontronite, intermediate in the case of T-N, and trioctahedral for T-S. Magnesium is 
abundant in the octahedral sheet of all samples but almost completely absent from the interlayer. Iron is logically abundant in G-N, nontronite and T-N, and also in many of the T-S samples. Two thirds of the submarine samples contain tetrahedral Fe. Only samples with non-expanding layers (talc, glauconite) contain $\mathrm{Fe}^{2+}$. The terrestrial samples analyzed for comparison are more Al-rich than the submarine samples. The difference between the layer charge from lattice cations (tetrahedral and octahedral) and interlayer cations is approximately zero (last column in Table 4). The frequent tetrahedral Fe presence in the submarine samples is not surprising as Fe is known to enter tetrahedral sites in Fe-rich, Al-depleted environments (Cole, 1988; Gates et al., 2002).

Traditionally, glauconite has been considered to originate in pelagic environments in connection with decaying organic matter, whereas celadonite has been considered to have an inorganic origin. However, different authors and nomenclature committees have defined the chemical and structural fields of both minerals and they advise that the names are used in reference to such characteristics, not considering the specific origin (Bailey, 1980; Rieder et al., 1998). We follow this norm. The non-expanding layers in the Fe-rich dioctahedral specimens appear to be within the definition of glauconite, because the octahedral Mg content (average for smectite and nonexpandable layers) is low for celadonite and generally coincident with that defined for glauconite.

\section{Discussion}

\subsection{Test for the XRD modeling}

The low crystallinity of many of the samples and their complexity (several interstratified phases in many of them) increases the uncertainty of the layer composition obtained by means of XRD pattern modeling of the glycolated mounts. The validity of these results was tested by plotting the total \% smectite layers from each sample versus the proportion of hydration water $(25-200 \mathrm{C})$ that was measured in the TG analyses (Fig. 6). The result is a good correlation, which indicates that the outcome of the XRD modeling is accurate. A large portion of the scatter in the plot is likely due to the TG results, rather than XRD values, because smectite in different samples would probably contain different proportions of water due to different interlayer cations and layer charge, and because there are contaminant phases that alter the relative weight of hydration water in the 
sample.

The only evident outlier in the plot is sample Va1-52KH-323-327, which contained $~ 70 \%$ gypsum (according to S and Ca contents). In this sample, the clay contained 67\% smectite layers (Table 2). In order to test that the large gypsum content placed this sample off the correlation in Figure 6, we performed experiments (results not shown) of mixtures of pure saponite and gypsum that revealed that the water loss in sample Va1-52KH-323-327 matches a 70:30 gypsum:clay mixture, where the clay has $67 \%$ smectite layers.

\subsection{Molecular water held in talc and glauconite layers}

The existence of strongly held water in talc layers, linked to octahedral $\mathrm{Fe}$, from submarine hydrothermal specimens, was described by Cuadros et al. (2008). Further evidence of this occurrence was found in this study (Fig. 7). The water loss measured by means of TG in the range 200-300 C correlates well with octahedral Fe content $\left(\mathrm{Fe}^{2+}+\mathrm{Fe}^{3+}\right)$ in T-S samples except for one sample (included in the correlation). Grimsey Graben samples do not appear in Fig. 7 because their weight loss at this temperature range is due mainly to loss of organic matter. Sample Va1$52 \mathrm{KH}-323-327$ is also omitted because it contains 70\% gypsum by weight. The outlier is Va3413KH-382-389, which contains $90 \%$ saponite layers. Talc-nontronite as well as G-N and nontronite samples also contain this strongly-held water, although there is no apparent correlation with octahedral Fe content (Fig. 7a). The corresponding values of \% water loss for nontronite are $0 \%, 0.9 \%$, and $2.1 \%$, the latter very likely due totally or in part to a contaminant phase.

In all these samples, retention of molecular water is likely to take place primarily in talc and glauconite layers, where water can be retained at such high temperature, in agreement with the description of Cuadros et al. (2008) for T-S and Drits and McCarty (2007) for illite. In order to test this hypothesis the smectite layers must be somehow subtracted. It is not possible to know the actual average composition of the talc layers in T-S or T-N, but we assumed that octahedral Fe content is similar for all layers in each interstratified phase. This might not be considered a problem for T-S, where the two layers are more similar in nature, although it could be with T-N. The 
corresponding values for talc in T-N are high, within 1.5-1.8 Fe atoms per $\mathrm{O}_{10}(\mathrm{OH})_{2}$ (Table 4). However, such values are not necessarily impossible because sample $1183-9$, a T-S with only $2 \%$ saponite layers, contains 1.3 octahedral Fe. It is plausible that T-N contains more octahedral Fe in talc layers than T-S does. Accordingly, we assessed octahedral Fe in talc layers using the formula Oct Fe $($ in talc $)=$ Average Oct Fe $\times$ Fraction of talc layers. There is an improved correlation for TS. Also, a good correlation emerges between this assessed octahedral Fe and the corresponding amount of strongly held water in T-N (Fig. 7b), with only one T-N sample plotting out of the pattern (full square, not included in the correlation) for which we cannot account.

The same assessment was carried out to investigate possible chemical links with strongly held water in G-N (Fig. 7c). No correlation emerged with octahedral Fe, but was observed with tetrahedral Fe. In this case the formula used to assess the tetrahedral Fe in glauconite layers was Tet Fe $($ in glauconite $)=$ Average Tet Fe $\times$ Fraction of glauconite layers. Overall, it appears that non-expanding layers retain molecular water that is somehow linked to $\mathrm{Fe}$ in the lattice. The nature of this link seems to be mainly related to the electronic properties of $\mathrm{Fe}$, rather than to a local charge imbalance created by the presence of $\mathrm{Fe}$ ions, because the link is to both $\mathrm{Fe}^{3+}$ and $\mathrm{Fe}^{2+}$ in the octahedral sheet. The charge imbalance was considered by Cuadros et al. (2008) who assumed only $\mathrm{Fe}^{3+}$ in their structural formulas of T-S. However, the present data indicate substantial $\mathrm{Fe}^{2+}$ in some samples (Table 4). There is a necessary charge imbalance created by the substitution of $\mathrm{Fe}^{3+}$ for $\mathrm{Si}^{4+}$ in the tetrahedral sheet of G-N. However, this imbalance alone is not the cause of the link with water, because tetrahedral Al does not have an effect on it.

The existence of molecular water trapped in non-expanding layers formed in Fe-rich environments, whether talc or glauconite in our case, is relevant to the spectral investigation of clay on Mars, where the chemical composition of very ancient (Noachian) crustal clays is similar to those encompassed by the samples in our study. Molecular water could also exist in talc- and glauconitelike layers on Mars. The detection of the molecular-water band at $1.9 \mu \mathrm{m}$ in near-IR Martian spectra of Fe/Mg-rich 2:1 clays, when it has a small to moderate size, may not necessarily imply the presence of smectite. Molecular water trapped in non-expandable clay layers would be much 
more resilient to evaporation in the very dry Martian atmosphere than smectite interlayer water.

\subsection{Chemistry of the octahedral sheet and dehydroxylation temperature}

It was typical of the analyzed samples that there were several dehydroxylation events in the clay. To investigate possible causes of these multiple events, those TG weight losses that corresponded to dehydroxylation events with a large degree of certainty (some samples were affected by contaminant phases, see Figure 4, sample Va3-413KH-150-153) were quantified. The corresponding dehydroxylation weight losses at individual temperatures were expressed as \% relative dehydroxylation for each sample. Using relative \% values that only include dehydroxylation events generates values unaffected by contaminants, whether these contaminants generated gases during the experiments or not.

The types of layers present in our samples are talc, saponite, both of which dehydroxylate at 700$900 \mathrm{C}$ in mineral endmembers, and nontronite, which dehydroxylates at 300-500 C. We observed that the major dehydroxylation event corresponded to the most abundant type of layer in the samples, but there was not a good correlation between both values. Thus, we did not assume that non-expanding layers (talc and glauconite) and smectite layers (nontronite and saponite) detected by means of $\mathrm{XRD}$ are true mineral end-members, which is problematic in interstratified clay minerals (Cuadros, 2010). Instead, we related the dehydroxylation events to the chemistry of the octahedral sheet in the average structural formulas. This approach considers the existence of octahedral domains with different compositions and occupancies, without tying these domains to expandable or non-expandable layers.

In the T-N series, divalent cations can be considered as more abundant in trioctahedral domains, and promote dehydroxylation above the range usual for nontronite (300-500 C). Thus, the relative proportion of dehydroxylation $>500 \mathrm{C}$ (specifically, 612-652 C in our samples) can be expected to correlate with the sum of octahedral $\mathrm{Mg}, \mathrm{Fe}^{2+}$ and $\mathrm{Mn}$. Most samples are within a single correlation curve that crosses the axes at the value $(0,0)$ (diamonds in Fig. 8a). Three other samples (squares) are outside the main trend. They are the terrestrial CRB-03-026, a mixture of celadonite 
and saponite (25\% saponite), at $23 \%$ dehydroxylation above $500 \mathrm{C}$, and two submarine samples, Cy-82-14-5 (100\% nontronite) and CHN-100-18PC-290-292 (68\% nontronite). These three data points have in common that significant proportions of divalent atoms generate lower or no dehydroxylation above $500 \mathrm{C}$. This suggests that the efficiency of divalent atoms in producing effective trioctahedral environments is dependent on cation distribution in the octahedral sheet. The main group of samples indicates a divalent cation distribution that is effective in generating trioctahedral domains (perhaps random, see discussion below). The slope of the curve is rather steep, proving that talc and nontronite domains are not in separate layers. This can be assessed in the following way. The dashed line in Figure 8a represents the effect on dehydroxylation temperature of the mixture of an ideal dioctahedral smectite (2 trivalent cations per $\mathrm{O}_{10}[\mathrm{OH}]_{2}$ ) and an ideal trioctahedral smectite (3 divalent cations per $\mathrm{O}_{10}[\mathrm{OH}]_{2}$ ). It represents the case in which dioctahedral and trioctahedral environments are in different layers. The behavior of our samples is different from this model (Fig. 8a). Calculations that allow for realistic substitutions of divalent cations in the trioctahedral layers, and of trioctahedral cations in the dioctahedral sheets can displace slightly the dashed line laterally and change, also slightly, its slope, without altering them substantially. Thus, the arrangement of divalent cations in the octahedral sheet for the main group of the nontronite and T-N samples is intermediate between dispersion and complete segregation (or separate layers) and such that it is efficient in generating trioctahedral domains. Further proof that the domains are not in separate layers is given by the dehydroxylation temperature of the trioctahedral domains in T-N, with peaks at $612-652 \mathrm{C}$, below the usual talc range $700-900 \mathrm{C}$. The lower dehydroxylation temperature is very likely due to the small size of the trioctahedral domains. Even if the di- and trioctahedral environments are not in separate layers, some (or most) of them are sufficiently large to contain complete coherent diffraction domains, which is indicated by the fact that T-N samples had two 060 maxima, corresponding roughly to each of these octahedral environments (Fig. 2). The two samples (open squares) with no dehydroxylation $>500 \mathrm{C}$ suggest dispersion of divalent cations in the sheet, so no effective trioctahedral domains are formed. Sample CRB-03-026 is different in character, because it is a mixture of two end-members, rather than a mixed-layer phase. 
In the group formed by the nontronite and G-N samples (Fig. 8b), where all layers are Fe-rich and dioctahedral, the assumption is that octahedral $\mathrm{Mg}$ and $\mathrm{Al}$ can generate domains that are montmorillonitic, illitic or celadonitic. Their specific character does not matter in particular, the important fact is that all these minerals dehydroxylate at higher temperature than nontronite and glauconite, precisely because of their higher $\mathrm{Al}$ and $\mathrm{Mg}$ contents. The dehydroxylation events above $500 \mathrm{C}$ had maxima in the range 536-675 C. Plotting the sum of octahedral $\mathrm{Al}$ and $\mathrm{Mg}$ versus the relative proportion of dehydroxylation above $500 \mathrm{C}$ reveals a correlation for all samples but two. Again, there is a steep increase in the weight loss above $500 \mathrm{C}$. This correlation line does not cross the axes at $(0,0)$, indicating that there is a minimum number of $\mathrm{Al}$ and $\mathrm{Mg}$ needed to induce dehydroxylation above that typical for glauconite or nontronite. The two outliers are the terrestrial Glauconite $97(\mathrm{Al}+\mathrm{Mg}=0.47)$ and the submarine nontronite Cy-82-14-5, also an outlier in the T-N and nontronite plot discussed above. It is also possible here that the different behaviour is related to a different cation distribution.

Finally, with the group of trioctahedral clays, T-S, the assumption was that trivalent ions and Ti may promote the formation of dioctahedral domains, which would dehydroxylate below $700 \mathrm{C}$. We found dehydroxylation events that had maxima in the range 598-728 C. Although there is overlap with the range of dehydroxylation of saponite and talc, these peaks were clearly different from those of the main dehydroxylation events at higher temperature. In this case, there is more scattering of the data points (Fig. 8c), and no identifiable trend that is supported by a good correlation. It is also possible that the dehydroxylation temperature was controlled by the talc-like versus saponite-like character of the layers, but there is no correlation between the relative proportions of talc and saponite layers and the relative weight loss at the two dehydroxylation events.

\subsection{Octahedral composition and polar layers}

The trends identified in the temperature of dehydroxylation of the mixed-layer clays linked to the octahedral chemistry open new avenues to the investigation of the octahedral cation distribution and how the octahedral cation composition changes in interstratified systems. The slopes found in 
the two trends that could be identified indicate that there is no direct correspondence between expandable and non-expandable layers and the octahedral chemistry. In other words, the expanding behaviour is dictated by the chemistry of the layers, but the tetrahedral and octahedral sheets within one layer may have compositions that do not correspond to the same end-member, either in the entire layer or in domains within it. Thus, while the expanding behaviour of the layer may be dictated by the composition of the greater part of the layer or by that of the tetrahedral sheet only, domains in the octahedral sheet can have a chemistry different from the rest and/or incongruent with that of the tetrathedral sheet.

This issue can be further investigated by considering the occupancy of the octahedral sheet. A plot of the divalent and trivalent (plus Ti) cations generates a regression line that ties the values 2 and 3, corresponding to the total occupancy in the dioctahedral and trioctahedral end-members, respectively (Fig. 9). The great majority of the samples gather near the two end-member fields. Only two samples are within the region of intermediate di- and trioctahedral composition, both terrestrial, the celadonite/saponite mixture CRB 03-026 and the nontronite/T-N mixture "Nontronite $51 "$. It is interesting to see that all submarine T-N samples fall within the dioctahedral range. The evidence for talc and nontronite layers in these samples is provided by the analysis of the oriented XRD patterns, by the existence of two XRD 060 peaks, and by the IR data. We calculated the ideal occupancy for all the T-N samples from the talc and nontronite layer composition obtained from $\mathrm{XRD}$, assuming ideal occupancies for talc and nontronite layers of 3 and 2, respectively. All the calculated values are within the intermediate di-trioctahedral field (Fig. 9). The terrestrial sample Nontronite 51 (full circle within di-tri field) plots relatively close to the corresponding calculated value (uppermost calculated value), whereas all the submarine samples contain more trivalent cations and less divalent cations than the calculations. This fact indicates that talc layers (as detected by $\mathrm{XRD}$, in the analysis of both 060 peaks and oriented mounts) contain significant octahedral Fe, Al, and Ti substitution, mainly Fe, because the other two cations are in low abundance.

Such a situation is perfectly feasible if the layers in T-N are "polar". The concept of polar layers in 
interstratified clay minerals was first introduced to explain the expanding behavior of illite-smectite mixed-layer (Lagaly, 1979) and confirmed later using NMR spectroscopy (Altaner et al., 1988). The concept indicates that the layers, from the point of view of XRD analysis, are defined by the interlayer space and the two surrounding tetrahedral sheets, whereas the octahedral sheets are the border between two different types of layers (Fig. 10). In this situation, the octahedral sheets are undefined in their chemistry and it is expected that they are composed of domains characteristic of one and the other type of tetrahedral-interlayer-tetrahedral unit that the octahedral sheets have at each side. From the above analysis, we can conclude that in our T-N samples, across all layers, the fraction of octahedral sheet units with a nontronite composition is larger than the fraction of expandable interlayers. This can be visualized considering that the octahedral sheets in polar layers (i.e., in tetrahedral-octahedral-tetrahedral units of mixed talc-nontronite character) have a total volume of dioctahedral domains larger than that of trioctahedral domains. The response of these domains to XRD analysis in the $b$ crystallographic direction (060 peak analysis) is complex, as it depends on their size and their relative scattering capacity (depending on number of cations and the number of electrons in their electronic shells). The existence of diand trioctahedral domains in T-N samples is evident from XRD (Fig. 2), but their exact composition and size cannot be deduced only from the analysis of the 060 peaks.

If T-N has a polar layer structure, which implies the existence of octahedral sheets with di- and trioctahedral environments, it is probable that T-S and G-N are also composed of polar layers, because the octahedral sheets have similar composition and occupancy and the structural strain in the polar layers is much less than in T-N. However, the similarity of the octahedral chemistry of the corresponding layer types of T-S and G-N precludes ascertaining this fact using the analysis applied to T-N.

\section{Conclusions}

The present study provides further evidence of the existence of interstratified clay minerals with diand trioctahedral layers, stressing that the chemical and structural differences between these types of layers are not an obstacle for their presence within the same crystal lattice. In fact, in mixed- 
layer clays, the octahedral sheet appears to be composed of domains of different crystal-chemical character that is not anchored to the chemistry of the tetrahedral sheets at each side. The lack of an exact match between octahedral chemistry of T-N specimens and their talc and nontronite layer content indicate that they are composed of polar layers, adding strength to the hypothesis that all interstratified clay systems have this polar structure.

The study shows how readily Fe and Mg can exchange for each other in clays. The exchangeability is maximum in trioctahedral systems because Fe can adopt both ferrous and ferric forms, adding flexibility to charge and size constraints. One of our T-S samples (1183-9) contains almost as much octahedral Fe as $\mathrm{Mg}$, and the total $\mathrm{Fe}$ (tetrahedral plus octahedral) is more than the Mg content. Material from this same sediment was analyzed by Alt et al (1987) and Cuadros et al (2008) and the three analyses show variable $\mathrm{Si}$, Fe and $\mathrm{Mg}$. This case demonstrates the heterogeneity of the compositions of submarine hydrothermal clays under the influence of local chemical conditions. The analyzed subsamples show the same mineral (T-S with $2 \%$ expandable layers) but with $\mathrm{Fe}_{2} \mathrm{O}_{3}$ content $17-22 \%$. The question arises whether further Fe for $\mathrm{Mg}$ substitution is possible.

Lastly, these results are highly relevant to understanding the nature of Fe-Mg-rich clays detected spectroscopically on Mars. Based on IR observations and interpretation of geologic context, it has been suggested that the vast majority of martian clays are smectitic, Fe-rich with variable amounts of $\mathrm{Mg}$ and extremely ancient (> 3.7 Ga; Poulet et al., 2005; Bibring et al., 2006; Murchie et al., 2009; Ehlmann et al., 2011). It is possible that the spectral detections do in fact represent clays that are purely smectitic with variable octahedral chemistry. However, another intriguing possibility is that many of the martian clays are in fact interstratified clays with both expandable and nonexpandable layers that can strongly retain water. This possibility could help to explain the preservation of clays that appear to be smectitic for billions of years, far beyond their typical preservation time on Earth. It could also help to explain how apparently smectitic clay preserves interlayer water in the dry conditions of the surface of Mars. Although Precambrian saponite has been reported on Earth (Bristow et al., 2009), indicating that lack of significant diagenetic 
processes may preserve smectite for an indefinite period of time, it is intriguing that so much smectite on Mars has escaped such diagenetic processes, that can take place not only by burial but also on the surface (Bristow and Milliken, 2011), for billions of years. Further, it is reasonable to expect that interstratified clays are abundant on Mars because they are generated, among other possibilities, by short-lived events not producing thorough mineralogical changes and by dynamic processes where changing physico-chemical conditions may result in heterogeneous reaction products (Cuadros et al., 2010; Cuadros, 2010). Such processes have probably been frequent in ancient Mars due to transient aqueous conditions at geological time-scale (Tosca et al., 2008). Unlocking clues to the origins of possible mixed-layer clays on Mars may be critical to understanding the chemical systems in which these compositionally variable clays formed in an ancient basaltic crust.

\section{Acknowledgments}

This study has been possible thanks to the generosity of the colleagues who provided the investigated samples: J. Scholten, A. Kraetschell, J. Broda, J. Alt, P. Lonsdale, R. Hekinian, S. Petersen, and M. Davydov. We thank E. A. Breves and M. Nelms for help with Mösbauer data processing. The study was funded by the IEF Marie Curie program of the EC (Hydro-Mars project).

\section{References}

Aldega, L., Cuadros, J., Laurora, A., Rossi, A., 2009. Weathering of phlogopite to beidellite in a karstic environment. Am. J. Sci. 309, 689-710. DOI 10.2475/08.2009.03

Alt, J.C., Lonsdale, P., Haymon, R., Muehlenbachs, K., 1987. Hydrothermal sulphide and oxide deposits on seamounts near $21^{\circ}$ N, East Pacific Rise. Geol. Soc. Am. Bull. 98, 157-168.

Altaner, S.P., Weiss, C.A. Jr, Kirkpatrick, R.J., 1988. Evidence from ${ }^{29}$ Si NMR for the structure of mixed-layer illite/smectite clay minerals. Nature 331, 699-702. 
Bailey, S.W., 1980. Summary of recommendations of AIPEA nomenclature committee. Clays Clay Miner. 28, 73-78.

Bibring, J.P., Langevin, Y., Mustard, J.F., Poulet, F., Arvidson, R., Gendrin, A., Gondet, B., Mangold, N., Pinet, P., Forget, F., and the OMEGA team, 2006. Global mineralogical and aqueous Mars history derived from OMEGA/Mars express data. Science 312, 400-404.

Bishop, J.L., Murad, E., Dyar M.D., 2002. The influence of octahedral and tetrahedral cation substitution on the structure of smectites and serpentines as observed through infrared spectroscopy. Clay Miner. 37, 617-628.

Bishop, J.L., Pieters, C.M., Edwards, J.O., 1994. Infrared spectroscopic analyses on the nature of water in montmorillonite. Clays Clay Miner. 42, 702-716.

Bristow, T.F., Kennedy, M.J., Derkowski, A., Droser, M.L., Jiang, G., Creaser, R.A., 2009. Mineralogical constraints on the paleoenvironments of the Ediacaran Doushantuo Formation. P. Natl. Acad. Sci. USA 106, 13190-13195.

Bristow T.F., Milliken R.E., 2011. Terrestrial perspective on authigenic clay mineral production in ancient Martian lakes. Clays Clay Miner. 59, 339-358.

Buatier, M., Fruh-Green, G., Karpoff, A., 1995. Mechanisms of Mg-phyllosilicate formation in a hydrothermal system at a sedimented ridge (Middle Valley, Juan de Fuca). Contrib. Mineral. Petr. 122, $134-151$.

Chamley, H., 1989. Clay Sedimentology. Springer-Verlag, Berlin.

Cole, T.G., 1985. Composition, oxygen isotope geochemistry and origin of smectite in the metalliferous sediments of the Bauer Deep, southeast Pacific. Geochim. Cosmochim. Acta 49, 
Cole, T.G., 1988. The nature and origin of smectite in the Atlantis II Deep, Red Sea. Can. Mineral. 26, 755-763.

Cuadros, J., Dekov, V.M., Fiore, S., 2008. Crystal-chemistry of the mixed-layer sequence talc-talcsmectite-smectite from submarine hydrothermal vents. Amer. Mineral. 93, 1338-1348.

Cuadros, J., Nieto, F., Wing-Dudek, T., 2009. Crystal-chemical changes of kaolinite-smectite mixed-layer with progressive kaolinization, as investigated by TEM-AEM and HRTEM. Clays Clay Miner. 57, 742-750.

Cuadros, J., 2010. Crystal-chemistry of mixed-layer clays, in: Fiore, S., Cuadros, J., Huertas, F.J. (Eds.), Interstratified Clay Minerals: Origin, Characterization and Geochemical Significance. AIPEA (International Association for the Study of Clays) Educational Series, Pub. No. 1, Digilabs, Bari, pp. 11-33.

Cuadros J., Fiore S. and Huertas F. J. (2010). Introduction to mixed-layer clay minerals, in: Fiore, S., Cuadros, J., Huertas, F.J. (Eds.), Interstratified Clay Minerals: Origin, Characterization and Geochemical Significance. AIPEA (International Association for the Study of Clays) Educational Series, Pub. No. 1, Digilabs, Bari, pp. 1-10.

Cuadros, J., 2012. Clay crystal-chemical adaptability and transformation mechanisms. Clay Miner. 47, 147-164. doi 10.1180/claymin.2012.047.2.01

Decarreau, A., Grauby, O., Petit, S., 1992. The actual distribution of octahedral cations in 2:1 clay minerals: results from clay synthesis. Appl. Clay Sci. 7, 147-167.

Dekov, V.M., Cuadros, J., Shanks, W.C., Koski, R.A., 2008a. Deposition of talc-kerolite- 
smectite—smectite at seafloor hydrothermal vent fields: Evidence from mineralogical, geochemical and oxygen isotope studies. Chem. Geol. 247, 171-194.

Dekov, V.M., Scholten, J., Garbe-Schönberg, C.-D., Botz, R., Cuadros, J., Schmidt M., Stoffers P., 2008b. Hydrothermal sediment alteration at a seafloor vent field: Grimsey Graben, Tjörnes Fracture Zone, north of Iceland. J. Geophys. Res. 113, B11101, doi:10.1029/2007JB005526

Dekov, V., Boycheva, T., Hålenius, U., Petersen, S., Billström, K., Stummeyer, J., Kamenov, G., Shanks, W., 2011. Atacamite and paratacamite from the ultramafic-hosted Logatchev seafloor vent field (14² $45^{\prime} \mathrm{N}$, Mid-Atlantic Ridge). Chem. Geol. 286, 169-184.

Drits, V., Dainyak, L., Muller, F., Besson, G., Manceau, A., 1997. Isomorphous cation distribution in celadonites, glauconites and Fe-illites determined by infrared, Mösbauer and EXAFS spectroscopies. Clay Miner. 32, 153-179.

Drits, V., McCarty, D., 2007. The nature of structure-bonded H2O in illite and leucophyllite from dehydration and dehydroxylation experiments. Clays Clay Miner. 55, 45-58

Drits, V., Sakharov, B., Lindgreen, H., Salyn, A., 1997. Sequential structure transformation of illitesmectite-vermiculite during diagenesis of Upper Jurassic shales from the North Sea and Denmark. Clay Miner. 32, 351-371.

Dudek, T., Cuadros, J., Fiore, S., 2006. Interstratified kaolinite-smectite: Nature of the layers and mechanism of smectite kaolinization. Amer. Mineral. 91, 159-170.

Dyar, M.D., 1984. Precision and interlaboratory reproducibility of measurements of the Mössbauer effect in minerals. Amer. Mineral. 69, 1127-1144.

Dyar, M.D., McGuire, A.V., Ziegler, R.D., 1989. Redox equilibria and crystal chemistry of coexisting 
minerals from spinel Iherzolite mantle minerals. Amer. Mineral. 74, 969-980.

Dyar, M.D., Schaefer, M.W., Sklute, E.C., Bishop, J.L., 2008. Mössbauer spectroscopy of phyllosilicates: Effects of fitting models on recoil-free fractions and redox ratios. Clay Miner. 43, 333.

Ehlmann, B.L., Mustard, J.F., Murchie, S.L., Bibring, J.-P., Meunier, A., Fraeman, A.A., Langevin, Y., 2011. Subsurface water and clay mineral formation during the early history of Mars. Nature $479,53-60$.

Fialips, C.-I., Huo, D., Yan, L., Wu, J., Stucki, J., 2002. Infrared study of reduced and reducedreoxidized ferruginous smectite. Clays Clay Miner. 50, 455-469.

Gates, W., 2008. Cation mass-valence sum (cm-vs) approach to assigning $\mathrm{OH}$-bending bands in dioctahedral smectites. Clays Clay Miner. 56, 10-22.

Gates, W.P., Slade, P.G., Manceau, A., Lanson, B., 2002. Site occupancies by iron in nontronites. Clays Clay Miner. 50, 223-239.

Geatches, D.L., Clark, S.J., Grenwell, H.C., 2012. Iron reduction in nontronite-type clay minerals: Modelling a complex system. Geochim. Cosmochim. Acta 81, 13-27.

Grauby, O., Petit, S., Decarreau, A., Baronnet, A., 1994. The nontronite-saponite series: An experimental approach. Eur. J. Mineral. 6, 99-112.

Haase, K.M., Petersen, S., Koschinsky, A. and 31 others, 2007. Young volcanism and related hydrothermal activity at $5^{\circ} \mathrm{S}$ on the slow-spreading southern Mid-Atlantic Ridge. Geochemistry, Geophysics, Geosystems 8, doi:10.1029/2006GC001509 
Hannington, M., Herzig, P., Stoffers, P., Scholten, J., Botz, R., Garbe-Schönberg, D., Jonasson, I.R., Roest, W., and Shipboard Scientific Party, 2001. First observations of high-temperature submarine hydrothermal vents and massive anhydrite deposits off the north coast of Iceland. Mar. Geol. 177, 199-220.

Hekinian, R., Bideau, R., Francheteau, J., Cheminee, J.L., Armijo, R., Lonsdale, P., Blum, N., 1993. Petrology of the East Pacific Rise crust and upper mantle exposed in Hess deep (eastern equatorial Pacific). J. Geophys. Res: Sol. Ea. 98, 8069-8094. doi: 10.1029/92JB02072

Hekinian, R., Fouquet, Y., 1985. Volcanism and metallogenesis of axial and off-axial structures on the East Pacific Rise near $13^{\circ}$ N. Econ. Geol. 80, 221-249.

Huggett, J.M., Cuadros, J., 2010. Glauconite formation in lacustrine/palaeosol sediments, Isle of Wight (Hampshire basin), UK. Clay Miner. 45, 35-49, DOI 10.1180/claymin.2010.045.1.35

Kloprogge, J.T., Kristóf, J., Frost, R.L., 2003. Thermogravimetric analysis-mass spectrometry (TGA-MS) of hydrotalcites containing CO32-, NO3-, Cl-, SO42- or ClO4-. In 2001. A Clay Odyssey. Proceedings of the 12th International Clay Conference, Bahia Blanca, Argentina, July 22-28, 2001. Dominguez E., Mas G., Cravero F. editors. 8 pp. (pages are not numbered).

Köster, H., Ehrlicher, H., Gilg, H., Jordan, R., Murad E., Onnich, K., 1999. Mineralogical and chemical characteristics of five nontronites and Fe-rich smectites. Clay Miner. 34, 579-599.

Lagaly, G., 1979. The "layer charge" of regular interstratified 2:1 clay minerals. Clays Clay Miner. 27, 1-10.

Long, G.J., Cranshaw, T.E., Longworth, G., 1983. The ideal Mössbauer effect absorber thicknesses. Mössbauer Effect Reference Data Journal 6, 42-49. 
Lonsdale, P.F., Bischoff, J.L., Burns, V.M., Kastner, M., Sweeney, R.E., 1980. A high-temperature hydrothermal deposit on the seabed at a Gulf of California spreading center. Earth Planet. Sc. Lett. 49, 8-20.

Mehra, O.P., Jackson, M.L., 1960. Iron oxide removal from soils and clays by dithionite-citrate system buffered with sodium bicarbonate. Clays Clay Miner. 7, 317-327.

Moore, D.M., Reynolds, R.C. Jr, 1997. X-ray Diffraction and the Identification and Analysis of Clay Minerals, second ed. Oxford University Press, Oxford.

Murchie, S.L., Mustard, J.F., EhImann, B.L., Milliken, R.E., Bishop, J.L., McKeown, N.K., Noe Dobrea, E.Z., Seelos, F.P., Buczkowski, D.L., Wiseman, S.M., Arvidson, R.E., Wray, J.J., Swayze, G., Clark, R.N., Des Marais, D.J., McEwen, A.S., Bibring, J.-P., 2009. A synthesis of Martian aqueous mineralogy after 1 Mars year of observations from the Mars Reconnaissance Orbiter. J. Geophys. Res. 114, E00D06, doi:10.1029/2009JE003342

Neumann, A., Petit, S., Hofstetter, T., 2011. Evaluation of redox-active iron sites in smectites using middle and near infrared spectroscopy. Geochim. Cosmochim. Acta 75, 2336-2355.

Parfitt, R.L., Childs, C.W., 1988. Estimation of forms of Fe and Al: a review and analysis of contrasting soils by dissolution and Mössbauer methods. Aust. J. Soil Res. 26, 121-144.

Petersen, S., Kuhn, K., Kuhn, T., Augustin, N., Hékinian, R., Franz, L., Borowski, C., 2009. The geological setting of the ultramafic-hosted Logatchev hydrothermal field $\left(14^{\circ} 45^{\prime} \mathrm{N}\right.$, Mid-Atlantic Ridge) and its influence on massive sulfide formation. Lithos 112, 40-56.

Plançon, A., 2002. New modeling of X-ray diffraction by disordered lamellar structures, such as phyllosilicates. Amer. Mineral. 87, 1672-1677. 
Poulet, F., Bibring, J.-P., Mustard, J.F., Gendrin, A., Mangold, N., Langevin, Y., Arvidson, R.E.,

Gondet, B., Gomez, C., 2005. Phyllosilicates on Mars and implications for early martian climate. Nature 438, 623-627. doi:10.1038/nature04274

Rieder, M., Cavazzini, G., D’Yakonov, Y.S., Frank-Kamenetskii, V.A., Gottardi, G., Guggenheim, S., Koval, P.V., Müller, G., Neiva, A.M.R., Radoslovich, E.W., Robert, J.L., Sassi, F.P., Takeda, H., Weiss, Z., Wones, D.R., 1998. Nomenclature of the micas. Can. Mineral. 36, 905-912.

Rögnvaldsson, S., Gudmundsson, A., Slunga, R., 1998. Seismotectonic analysis of the Tjörnes Fracture Zone, an active transform fault in north Iceland. J. Geophys. Res. 103, 30117-30129.

Russell, J.D., Fraser, A.R., 1994. Infrared methods, in: Wilson, M.J. (Ed.) Clay Mineralogy: Spectroscopic and Chemical Determinative Methods. Chapman \& Hall, London, pp: 11-67.

Thompson, M., Walsh, J.N., 2003. Handbook of Inductively Coupled Plasma Atomic Emission Spectrometry. Viridian, Woking, UK.

Tosca, N.J., Knoll, A.H., McLennan, S.M., 2008. Water activity and the challenge for life on early Mars. Science 320, 1204-1207.

Weaver, C.E., 1989. "Authigenic marine" physils, in: Clays, Muds, and Shales. Developments in Sedimentology 44. Elsevier, Amsterdam.

Zieremberg, R.A., Shanks, W.C. III, 1983. Mineralogy and geochemistry of epigenetic features in metalliferous sediment, Atlantis II Deep, Red Sea. Econ. Geol. 78, 57-72.

Zierenberg, R.A., Shanks, W.C., 1988. Isotopic studies of epigenetic features in metalliferous sediment, Atlantis II Deep, Red Sea. Can. Mineral. 26, 737-753. 
Figure captions

Figure 1. XRD patterns of oriented and glycolated mounts of four selected specimens, representing the four group of samples (from top to bottom) T-S (Sea Cliff Dive 308-light), T-N (Va3-413KH-150153), G-N (Va22-146KS-612-614) and nontronite (1183-15). Grey traces correspond to the calculated patterns. Numerical peak labels are in $\AA$, and values in parenthesis correspond to the calculated patterns. Values with an asterisk correspond to non-basal peaks. Str stands for strontianite $\left(\mathrm{SrCO}_{3}\right)$, and the corresponding peak has a d-spacing of $3.57 \AA$.

Figure 2. XRD patterns in the 060 peak region of random powders of five selected specimens representing the four types of samples. From top to bottom: T-S (Sea Cliff Dive 308-light), two T-N samples (Va22-146KS-471-475 and Va22-146KS-575-577), G-N (Va22-146KS-612-614), and N (1183-15). D-spacing values are in $\AA$.

Figure 3. Relevant areas of the mid-IR spectra of four samples representative of the mineralogical groups found (top to bottom, T-S, T-N, G-N, nontronite). Values in parenthesis next to sample labels indicate the $\%$ smectite layers from XRD modeling. The band at $670-685 \mathrm{~cm}^{-1}$ in Fe-rich dioctahedral clays (three bottom spectra) is assigned to $\mathrm{Si}-\mathrm{O}$ and $\mathrm{Fe}-\mathrm{O}$ vibrations in the literature (see text).

Figure 4. TG and DTG diagrams of four samples corresponding to (top to bottom) T-S, T-N, G-N and nontronite. Va3-413KH-150-153 contained pyrite and some other contaminant phase, perhaps hydrotalcite. For this sample, gases detected in the EGA analysis are shown next to each thermal event, in decreasing order of abundance (from left to right and from top to bottom). $\mathrm{SO}_{\mathrm{x}}$ indicates $\mathrm{SO}_{2}+\mathrm{SO}_{3}$. Arrows indicate the position of the clay dehydroxylation events.

Figure 5. Mössbauer spectra of four representative samples and their calculated components. Components corresponding to octahedral $\mathrm{Fe}^{2+}$ are shown in dotted lines. The component parameters are shown in Table 3. For these samples, all components correspond to Fe in the 
clays.

Figure 6. Plot of the proportion of smectite layers from XRD modeling of the oriented, glycolated mounts, vs. the weight \% loss below $200 \mathrm{C}$ in the TG experiments. The outlier contained $\sim 70 \%$ gypsum and is not included in the correlation.

Figure 7. Plots of Fe content vs. the \% of molecular-water loss taking place above $200 \mathrm{C}$ in TG experiments. Samples for which this TG measurement was totally hindered by contaminant phases producing weight loss in the same temperature range are not included. a) The $x$-axis is total octahedral Fe (di and trivalent) per half formula unit $\left(\mathrm{O}_{10}[\mathrm{OH}]_{2}\right)$. b) The $\mathrm{x}$-axis is the assessed Fe (di- and trivalent) octahedral content in talc layers from the formula Oct Fe (in talc) = Average Oct Fe $\times$ Fraction of talc layers in the sample (see text). c) The x-axis is the assessed tetrahedral Fe content in glauconite layers from the formula Tet Fe (in glauconite) = Average Tet Fe $\times$ Fraction of glauconite layers in the sample (see text). Arrows indicate non-submarine samples.

Figure 8. Investigation of the relative proportion (weight loss) of dehydroxylation at different temperatures and the abundance of octahedral cations (per $\mathrm{O}_{10}[\mathrm{OH}]_{2}$ ) expected to promote dehydroxylation at the specified temperatures. a) Nontronite and T-N sample series, which contains di- and trioctahedral layers. The plot corresponds to the sum of divalent cations, normalized to total cation abundance, versus \% dehydroxylation above $500 \mathrm{C}$. The solid line is the best fit for the diamond data points. The dashed line is a calculation representing clay where diand trioctahedral environments are in different layers (see text). b) Sum of octahedral Mg and Al versus \% dehydroxylation above $500 \mathrm{C}$, for the series nontronite and G-N. c) Sum of Ti and trivalent cations versus \% dehydroxylation below $700 \mathrm{C}$. Arrows indicate non-submarine samples.

Figure 9. Plot of trivalent cations and Ti versus divalent cations in the octahedral sheet of the clays (per $\mathrm{O}_{10}[\mathrm{OH}]_{2}$ ). The line is the correlation for all samples. The two dashed lines indicate the field where composition is intermediate between di- and trioctahedral. Open circles are calculated occupancies for the T-N series based on the relative proportion of talc and nontronite layers from 
XRD (see text).

Figure 10. Sketch of interstratified talc (non-expandable) and nontronite (expandable) layers, following the polar and non-polar (or traditional) concepts. In polar layers, the layers are defined by the interlayer and centred on it; consequently the composition of tetrahedral and octahedral sheets may be inconsistent with each other. The traditional concept sees layers as the tetrahedraloctahedral-tetrahedral unit, with a consistent end-member composition. 
Table 1. Description of the investigated samples. The numbers in parenthesis in the sample labels indicate the depth (cm) of the sample in the core.

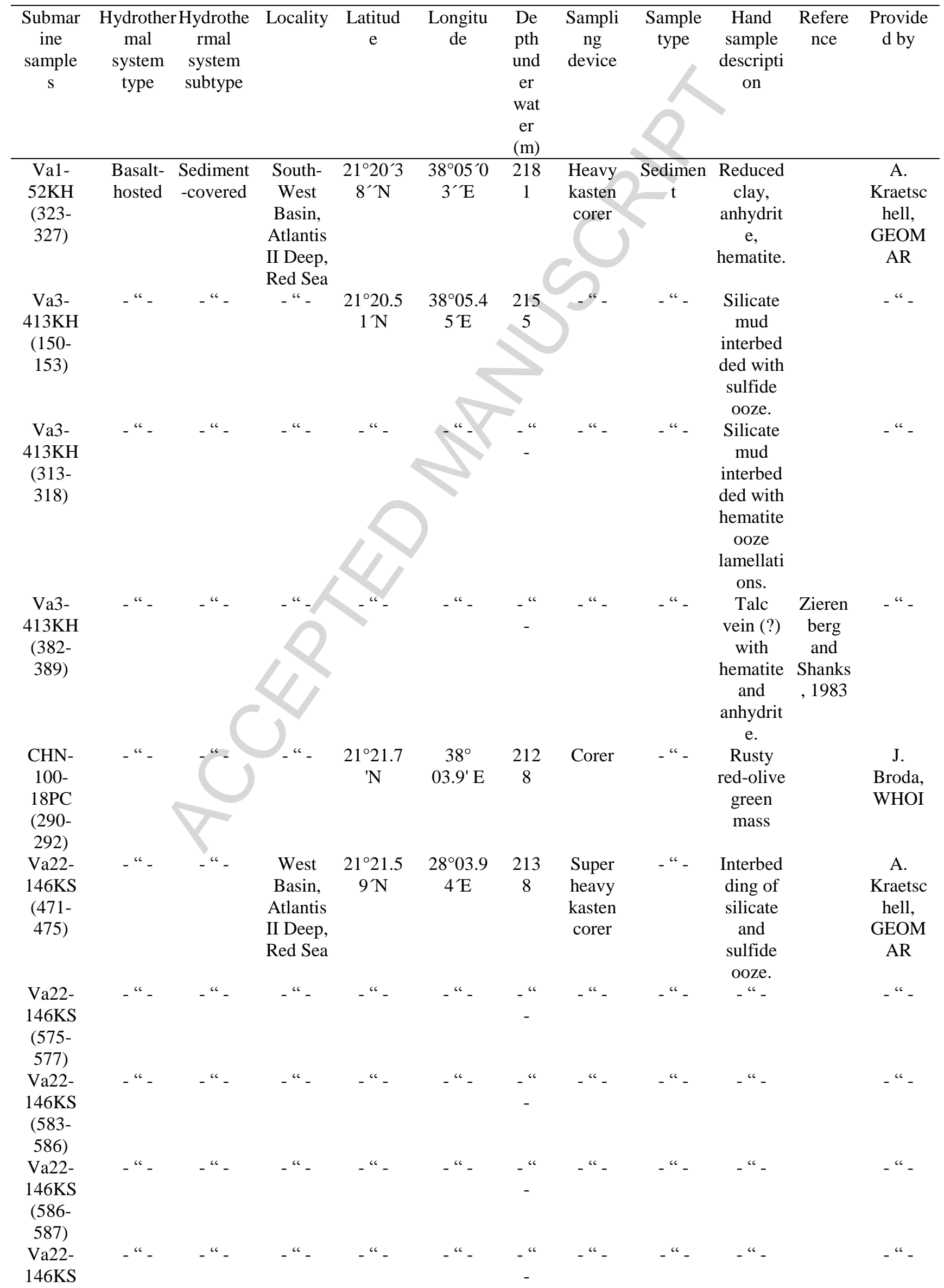


(588-

591)

Va22-

$146 \mathrm{KS}$

(602-

603)

Va22-

$146 \mathrm{KS}$

(603-

604)

Va22-

$146 \mathrm{KS}$

(612-

614)

Va22-

$146 \mathrm{KS}$

(639-

640)

Va22-

$146 \mathrm{KS}$

(1030-

1034)

Va22-

$146 \mathrm{KS}$

(1144-

1145)

Va22-

$146 \mathrm{KS}$

(1145-

1146)

Sea

Northern $27^{\circ} 18.3$

Cliff

Dive

308

$-"$ - _ $\quad$ - -
Trough
of

Guayma

s Basin,

Gulf of

Californi

a

POS-

291-

$459 \mathrm{SL}$

(20-21)
Grimsey $\quad 6^{\circ} 36.3 \quad 17^{\circ} 39.1396$ Gravity Sedimen Graben, 5' N 8' W Tjörnes

Fracture

Zone,

north of

Iceland
111³0. 200 Submer Fragmen 4 'W 0 sible ts of talc ledges

Light grey with rusty stains; light, crumbly, porous fragment s.

Olive Dekov gray to olive brown with graywhite casts.
Lonsd P. ale et Lonsdal al., e, SIO, 1980 UCSD.

POS-

291-

$459 \mathrm{SL}$

(31-32)

POS-

291-

$459 \mathrm{SL}$

(56-57)

POS-

291-

$459 \mathrm{SL}$

(72-73)

POS-

291-

$459 \mathrm{SL}$ 
(113-

114)

POS-

291-

$459 \mathrm{SL}$

(140-

141)

POS-

291-

$459 \mathrm{SL}$

(155-

158)

$1183-9$

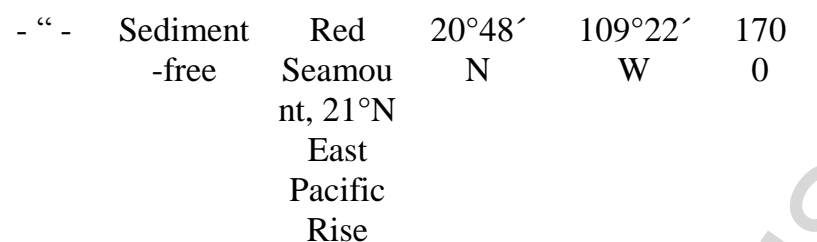

Solid Orangefragment brown to

s in the black, 1987

sediment light

chunks:
talc $(+$

Alt et J. Alt,

al., Univers

()

$\mathrm{FeOOH})$

$1183-$

15

- " - - - - - - -

$-\cdots$

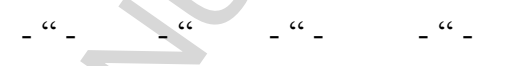

Dark-

green to

light-

green

fragment

s:

nontronit

e (+ Mn-

oxides).

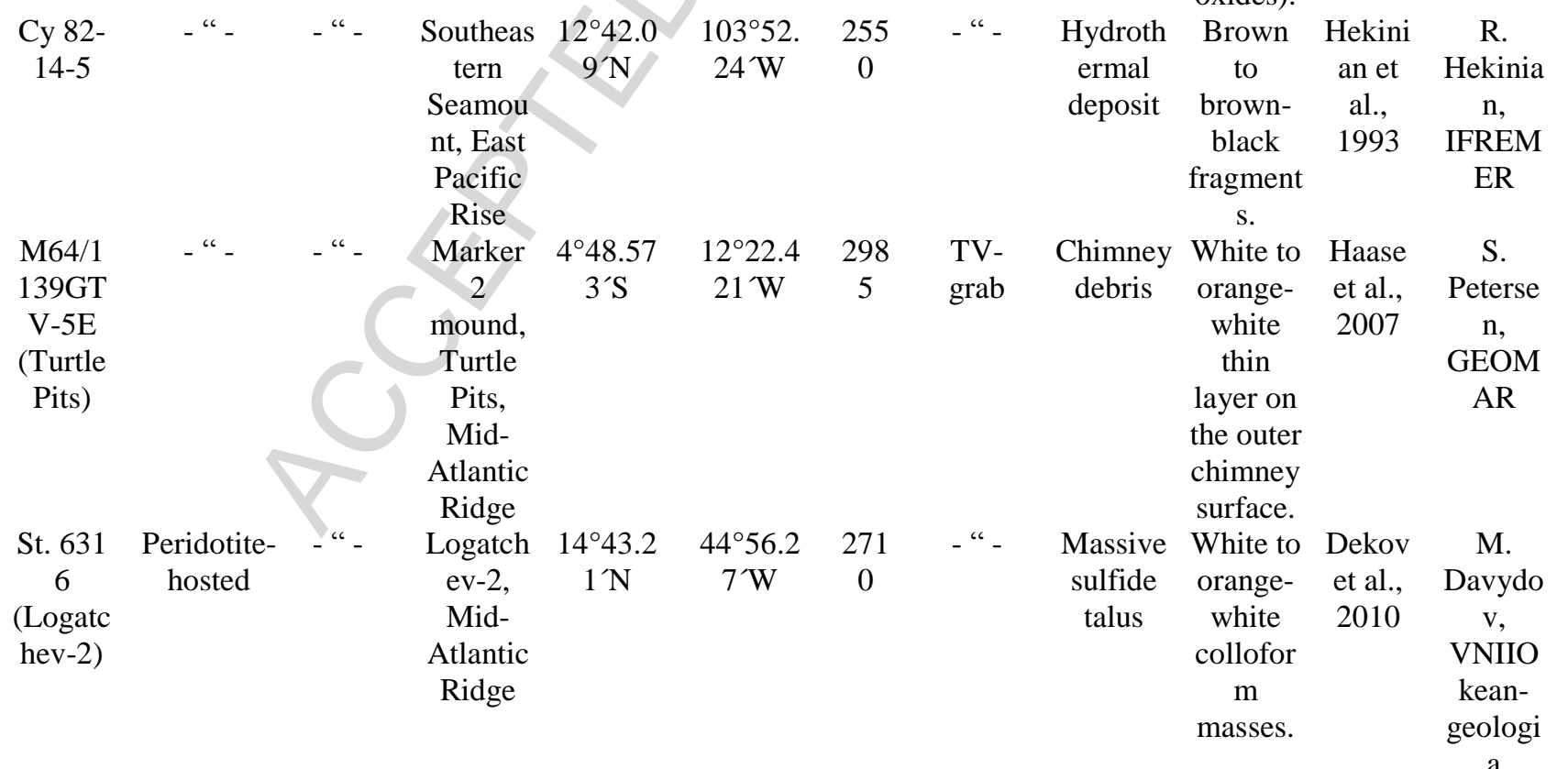

\begin{tabular}{|c|c|c|c|c|}
\hline $\begin{array}{l}\text { Non-marine } \\
\text { samples }\end{array}$ & Description & Locality & Reference & $\begin{array}{l}\text { Provide } \\
\mathrm{d} \text { by }\end{array}$ \\
\hline Galuconite 97 & $\begin{array}{l}\text { Glauconite-smectite from a green lacustrine } \\
\text { marl pedogenically modified. }\end{array}$ & Isle of Wight, UK. & $\begin{array}{l}\text { Huggett and } \\
\text { Cuadros, } 2010\end{array}$ & $\begin{array}{l}\text { J. } \\
\text { Huggett }\end{array}$ \\
\hline $\begin{array}{l}\text { Nontronite } \\
\text { 33B }\end{array}$ & $\begin{array}{l}\text { Nontronite product of the hydrothermal } \\
\text { alteration of the Columbia River Basalt }\end{array}$ & $\begin{array}{l}\text { Manito, Spokane County, } \\
\text { Washington, USA }\end{array}$ & $\begin{array}{l}\text { Köster et al., } \\
1999\end{array}$ & \\
\hline Nontronite 51 & $\begin{array}{l}\text { Contains nontronite and talc of unknown } \\
\text { origin. Thought to be part of the API } \\
\text { collection. }\end{array}$ & Unknown & & \\
\hline CRB 03-026 & $\begin{array}{l}\text { Celadonite from a hydrothermally altered } \\
\text { horizon at the contact of the Imnaha and } \\
\text { overlying Grande Ronde Basalt (Columbia } \\
\text { River Basalt Group). }\end{array}$ & $\begin{array}{l}\text { Collected along route } 129, \\
\text { south of Clarkston, Asotin } \\
\text { County, Washington, } \\
\text { USA. }\end{array}$ & & \\
\hline
\end{tabular}


Alt J.C., Lonsdale P., Haymon R., Muehlenbachs K. (1987) Hydrothermal sulphide and oxide deposits on seamounts near $21^{\circ} \mathrm{N}$, East Pacific Rise. Geological Society of America Bulletin 98, 157-168.

Dekov V.M., Scholten J., Garbe-Schönberg C.-D., Botz R., Cuadros J., Schmidt M., Stoffers P. (2008) Hydrothermal sediment alteration at a seafloor vent field: Grimsey Graben, Tjörnes Fracture Zone, north of Iceland. Journal of Geophysical Research 113, B11101, doi:10.1029/2007JB005526

Dekov, V.M., Petersen, S., Garbe-Schönberg, C.-D., Kamenov, G.D., Perner, M., Kuzmann, E., Schmidt, M. (2010) FeSi-oxyhydroxide deposits at a slow-spreading centre with thickened oceanic crust: The Lilliput hydrothermal field (9³3’S, Mid-Atlantic Ridge). Chemical Geology, 278, 186-200.

Haase K.M., Petersen S., Koschinsky A. and 31 others (2007) Young volcanism and related hydrothermal activity at $5^{\circ} \mathrm{S}$ on the slow-spreading southern Mid-Atlantic Ridge. Geochemistry, Geophysics, Geosystems 8 , doi:10.1029/2006GC001509

Hekinian R., Bideau R., Francheteau J., Cheminee J.L., Armijo R., Lonsdale P., Blum N. (1993) Petrology of the East Pacific Rise crust and upper mantle exposed in Hess deep (eastern equatorial Pacific). Journal of Geophysical Research: Solid Earth 98, 8069-8094. DOI: 10.1029/92JB02072

Huggett J.M. and Cuadros J. (2010) Glauconite formation in lacustrine/palaeosol sediments, Isle of Wight (Hampshire basin), UK. Clay Minerals, 45, 35-49, DOI 10.1180/claymin.2010.045.1.35

Köster H, Ehrlicher H, Gilg H, Jordan R, Murad E, Onnich K.(1999) Mineralogical and chemical characteristics of five nontronites and Fe-rich smectites. Clay Minerals 34, 579-99.

Lonsdale P.F., Bischoff J.L., Burns V,M., Kastner M., and Sweeney R.E. (1980) A high-temperature hydrothermal deposit on the seabed at a Gulf of California spreading center. Earth and Planetary Science Letters 49, 8-20.

Zieremberg R.A., and Shanks W.C. III (1983) Mineralogy and geochemistry of epigenetic features in metalliferous sediment, Atlantis II Deep, Red Sea. Economic Geology 78, 57-72. 
Table 2. Results of the modeling of the XRD patterns of oriented and glycolated mounts, and position of the 060 peaks from powder patterns. The error refers to total smectite content.

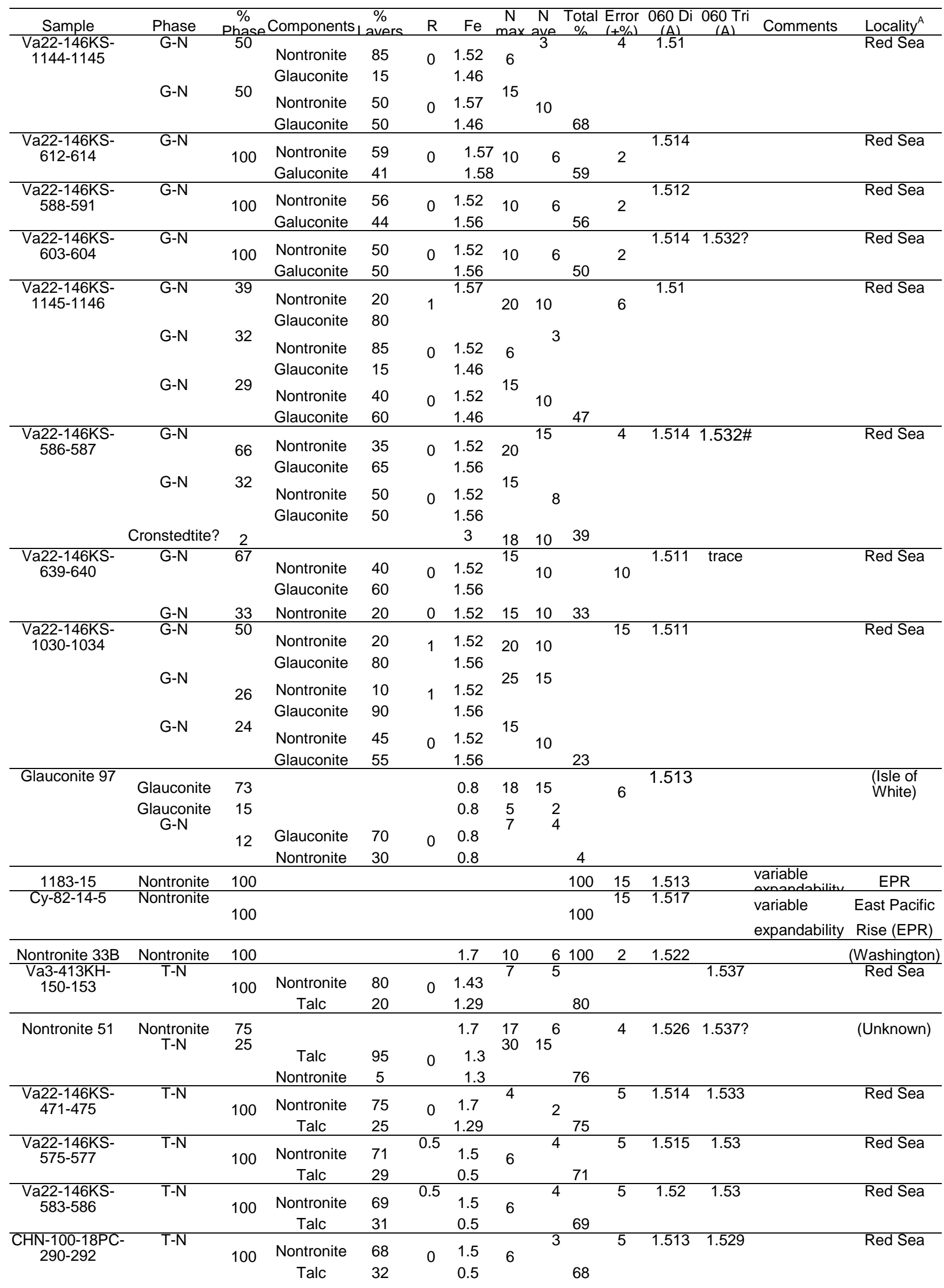




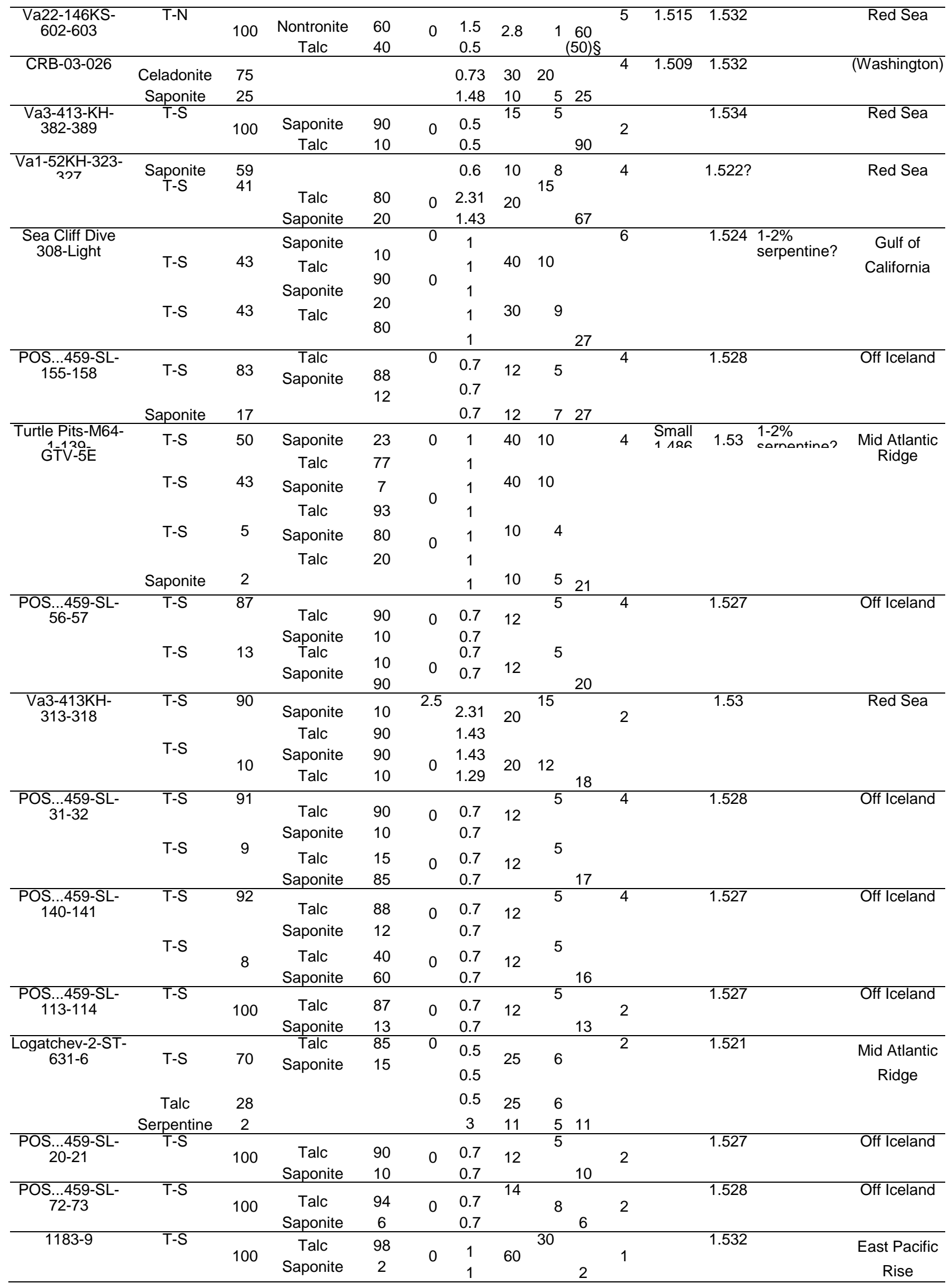

$\mathrm{d}$-smectite $=16.9 \mathrm{~A} ; \mathrm{d}$-talc $=9.3-9.4 \mathrm{~A} ; \mathrm{d}$-glauconite and celadonite $=9.98 \mathrm{~A} \mathrm{a}^{*}=20-40$

$\mathrm{R}=$ Layer stacking order 
$\mathrm{N} \max , \mathrm{N}$ ave $=$ Maximum and avarage number of layers in the coherent scattering domains Error $=$ number of phases $\mathrm{x}$ estimated error per phase $/ 2 \S$ Value in parenthesis is from 060 peak analysis.

${ }^{\mathrm{A}}$ Localities in parenthesis are non-submarine.

\# Small peak; possibly cronstedtite? 
Table 3. Mossbauer parameters for spectra in Figure 5.

\begin{tabular}{|c|c|c|c|c|}
\hline Sample & Va22...1030-1034 & $1183-15$ & Va3...150-153 & Sea Cliff Dive \\
\hline Mineralogy Velocity scale & & $\mathrm{N}$ & & \\
\hline$(\mathrm{mm} / \mathrm{s})$ & $\mathrm{G}-\mathrm{N}+/-4$ & $+/-4$ & $\mathrm{~T}-\mathrm{N}+/-4$ & $\mathrm{~T}-\mathrm{S}+/-4$ \\
\hline IS (mm/s) & 0.08 & 0.16 & 0.20 & 0.201 \\
\hline $\begin{array}{l}{ }^{[4]} \mathrm{Fe}^{3}+\mathrm{QS}(\mathrm{mm} / \mathrm{s}) \\
\text { Width }(\mathrm{mm} / \mathrm{s})\end{array}$ & $\begin{array}{c}0.64 \\
0.23^{*}\end{array}$ & $\begin{array}{l}0.65 \\
0.43\end{array}$ & $\begin{array}{l}0.77 \\
0.44\end{array}$ & $\begin{array}{c}0.99 \\
0.70^{*}\end{array}$ \\
\hline Area (\%) & 10 & 18 & 23 & 21 \\
\hline $\mathrm{IS}(\mathrm{mm} / \mathrm{s})$ & 0.40 & 0.37 & 0.36 & \\
\hline${ }^{[6]} \mathrm{Fe}^{3}+\mathrm{QS}(\mathrm{mm} / \mathrm{s})$ & 0.33 & 0.49 & 0.61 & \\
\hline Width $(\mathrm{mm} / \mathrm{s})$ & 0.43 & 0.51 & 0.41 & \\
\hline Area (\%) & 60 & 72 & 41 & \\
\hline IS (mm/s) & 0.47 & 0.52 & 0.44 & 0.54 \\
\hline${ }^{[6]} \mathrm{Fe}^{3}+\mathrm{QS}(\mathrm{mm} / \mathrm{s})$ & 1.08 & 1.14 & 0.96 & 0.96 \\
\hline Width $(\mathrm{mm} / \mathrm{s})$ & 0.37 & 0.31 & 0.51 & $0.50 *$ \\
\hline Area (\%) & 25 & 9 & 33 & 12 \\
\hline IS (mm/s) & 1.14 & & 1.00 & 1.14 \\
\hline${ }^{[6]} \mathrm{Fe}^{2}+\mathrm{QS}(\mathrm{mm} / \mathrm{s})$ & 1.84 & & 2.55 & 2.61 \\
\hline Width $(\mathrm{mm} / \mathrm{s})$ & 0.33 & & 0.29 & 0.24 \\
\hline Area (\%) & 6 & & 3 & 67 \\
\hline \multirow{2}{*}{$\begin{array}{c}2 \\
X \\
2 \\
\text { X norm }\end{array}$} & 1408.7 & 1396.9 & 547.4 & 346.1 \\
\hline & 2.6 & 2.7 & 1.1 & 0.7 \\
\hline
\end{tabular}

1Parameter fixed in the curve-fitting process.

IS = isomer shift.

QS = quadrupole splitting.

Width = full width at half maximum.

Area is expressed as percentage of the total peak area.

$C=$ Goodness of fit.

$x_{\text {norm }}=$ Goodness of fit normalized to number of data points. 
Table 4. Chemical formulas calculated for clay mineral samples based on corrected wet chemistry, Mossbauer analysis and IR spectra. The mineral phases and percent of smectite are added for reference.

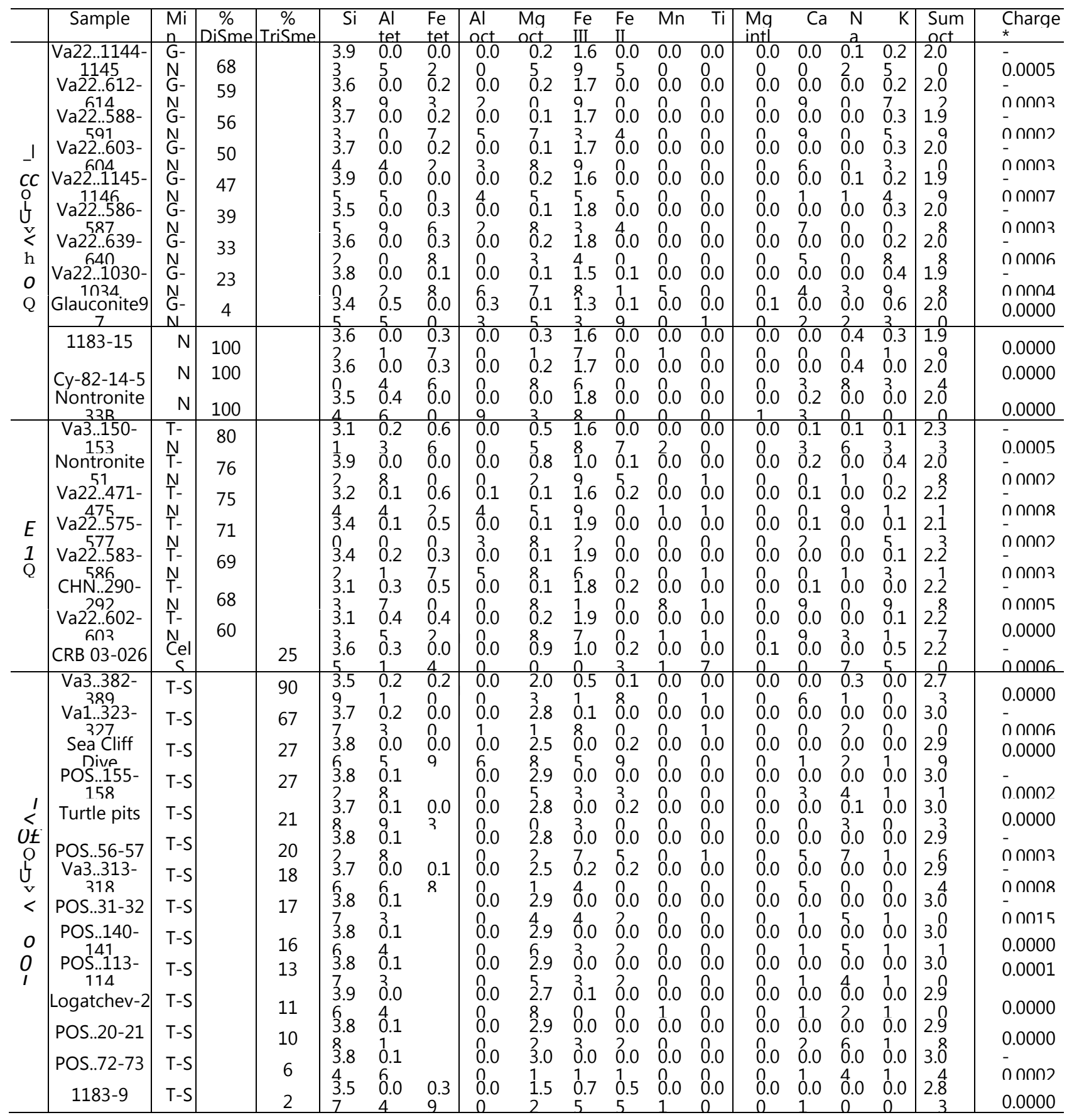

* Difference between charge of interlayer cations and charge calculated from the lattice cations. 
Figure 1

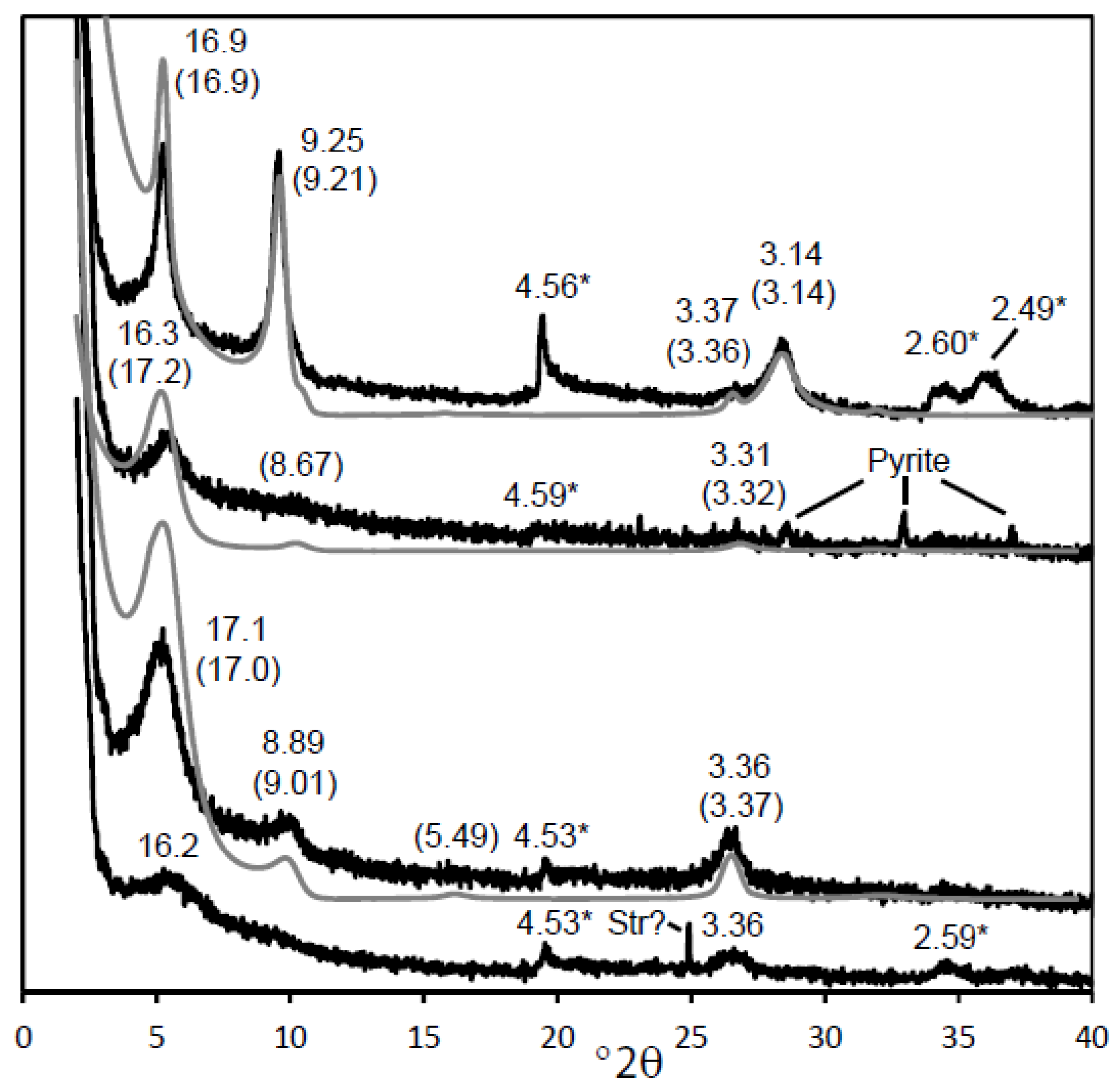


Figure 2

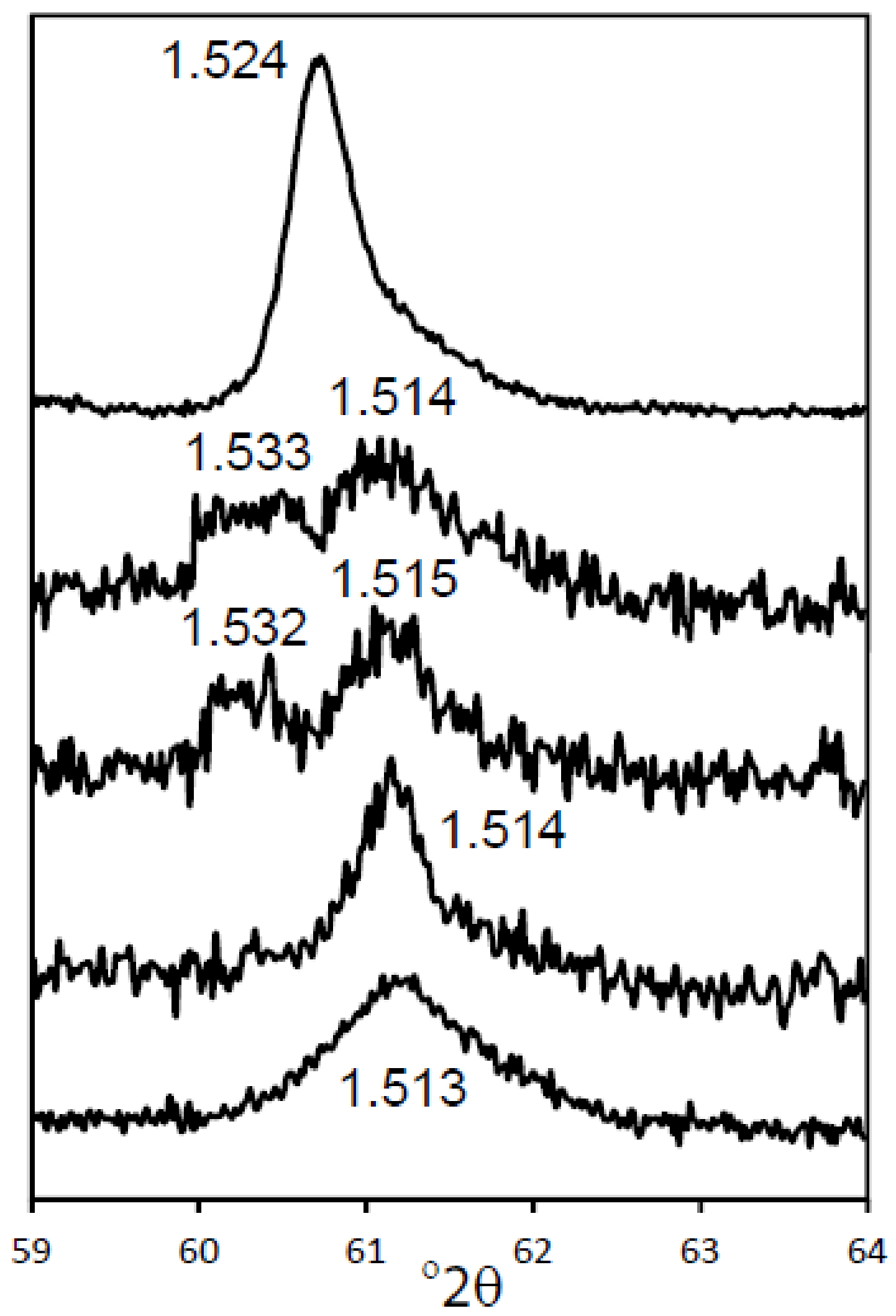




\section{Figure 3}

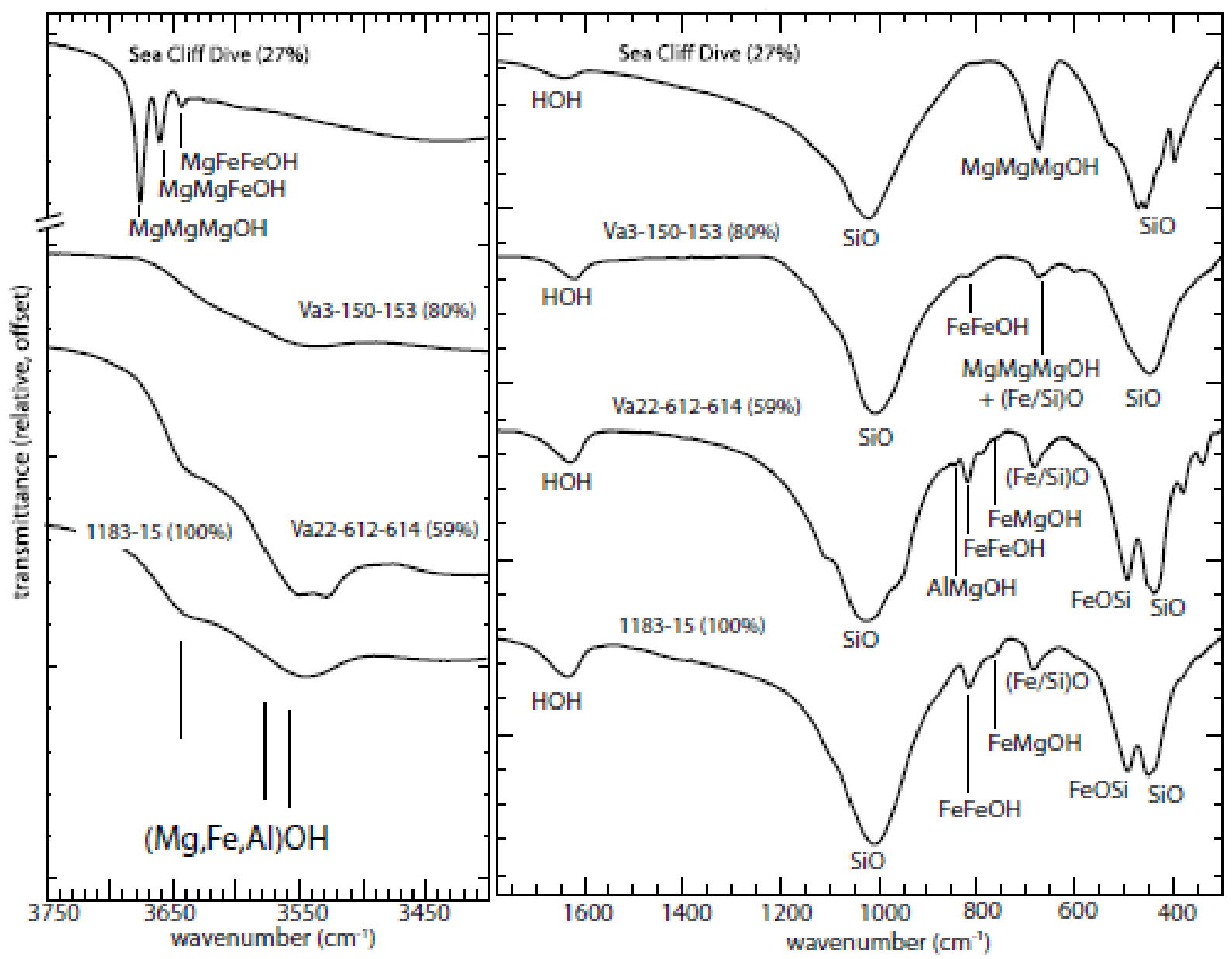


Figure 4

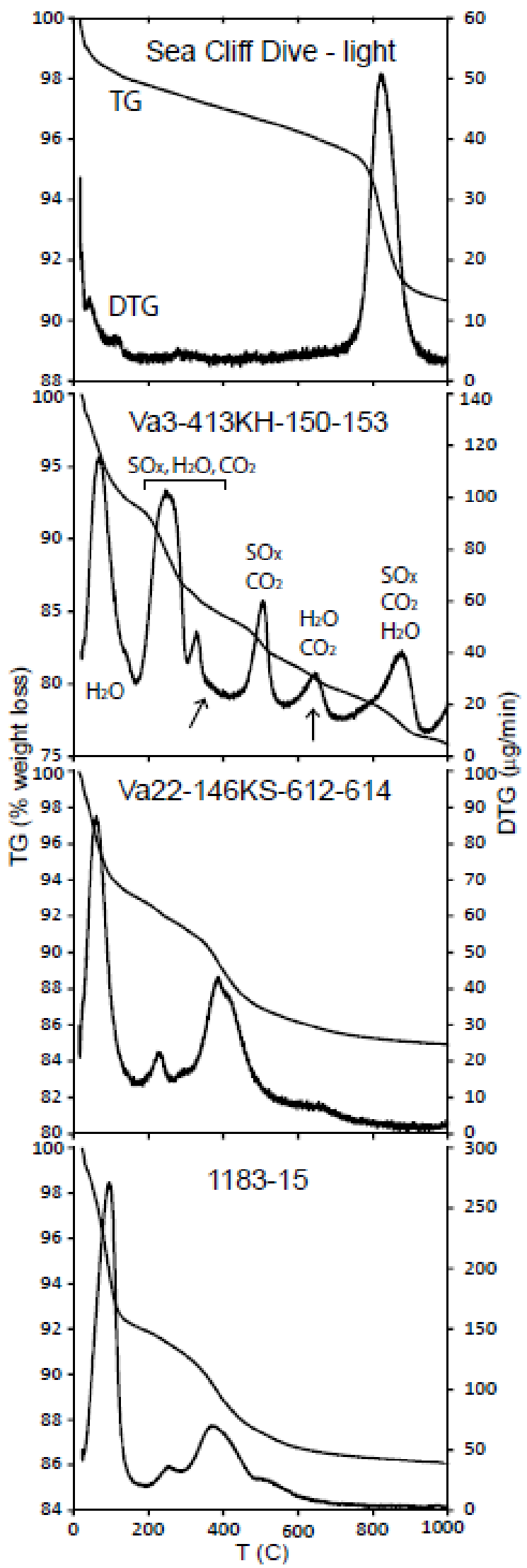


Figure 5

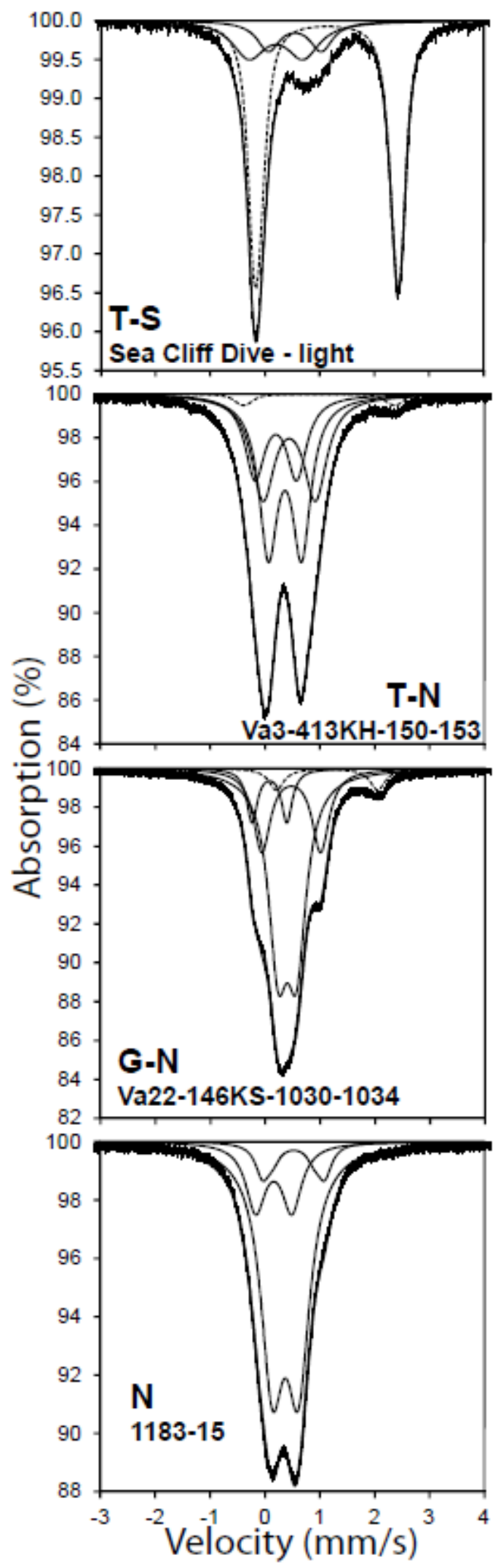


Figure 6

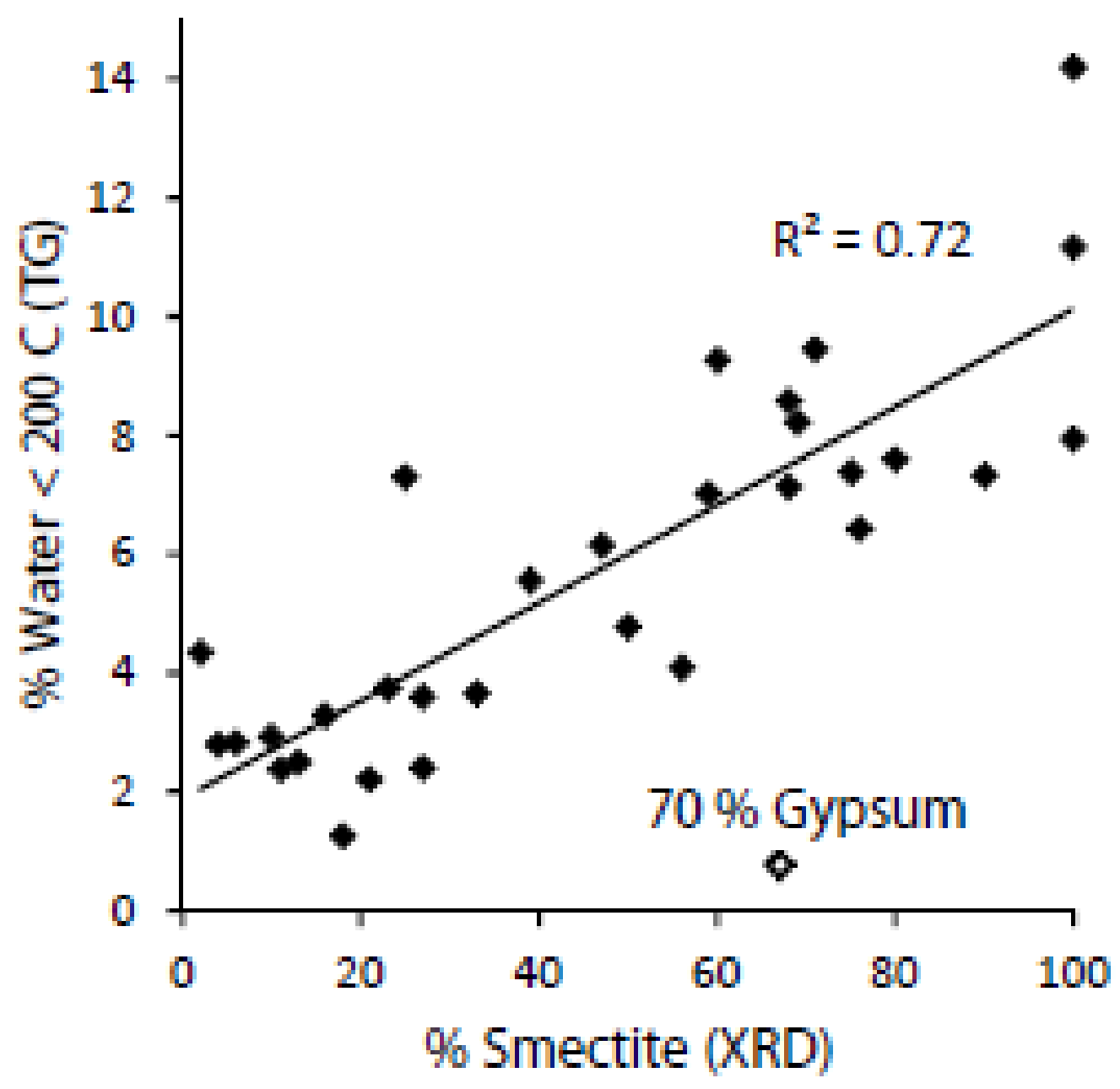


Figure 7
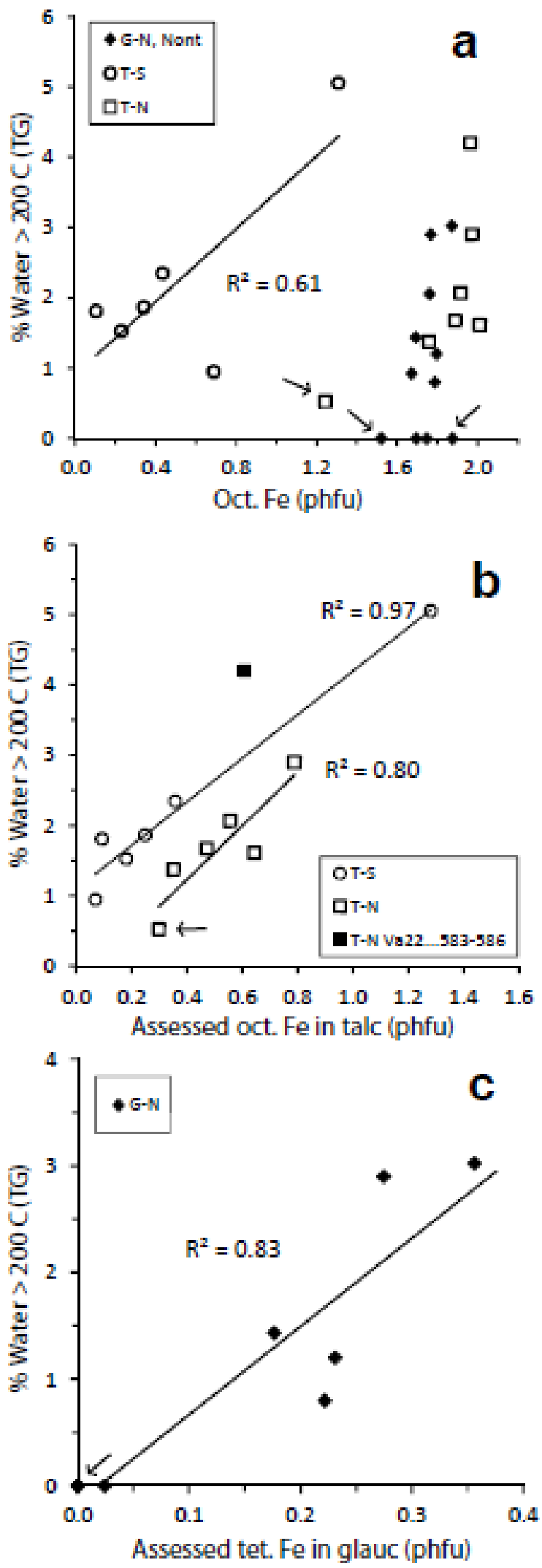
Figure 8
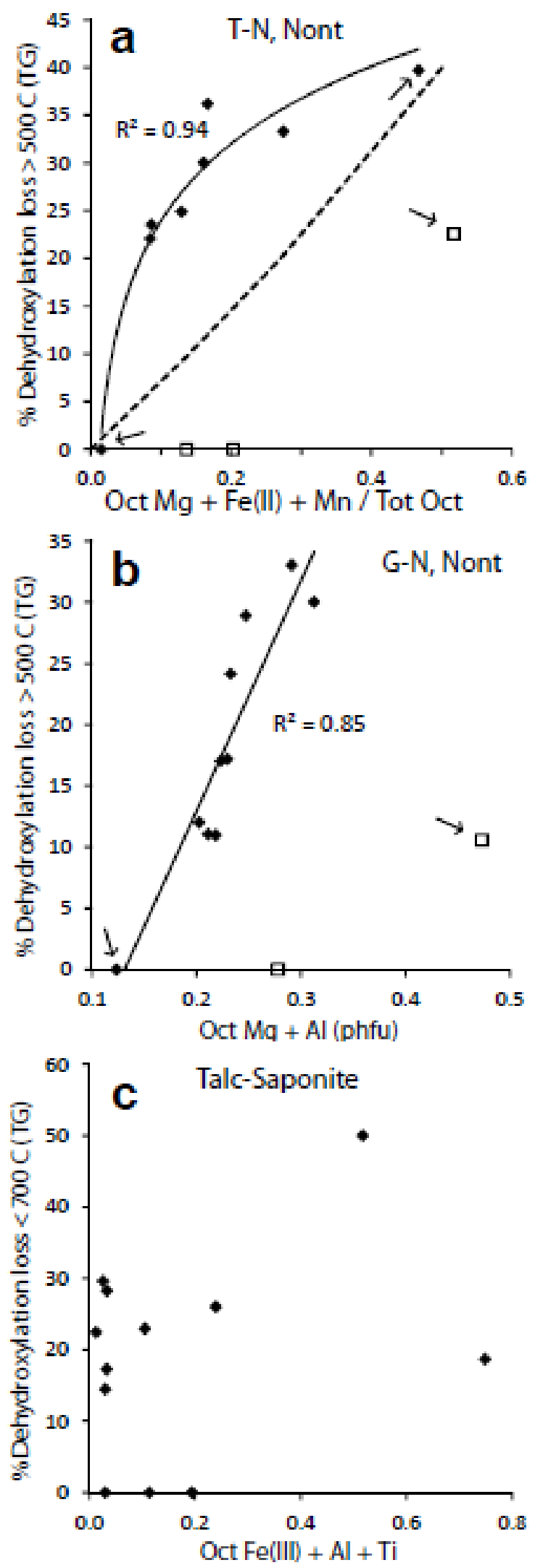
Figure 9

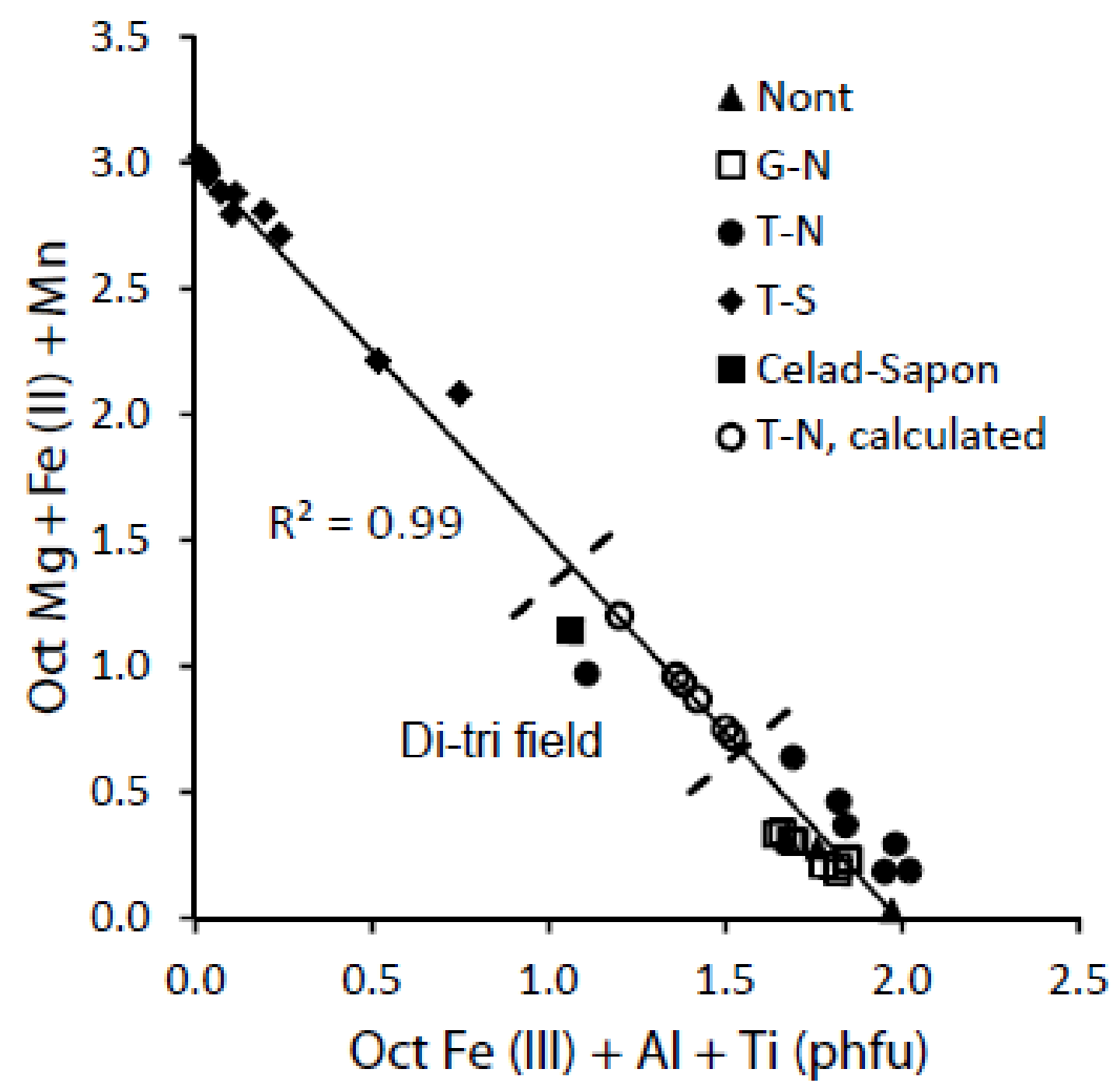


Figure 10

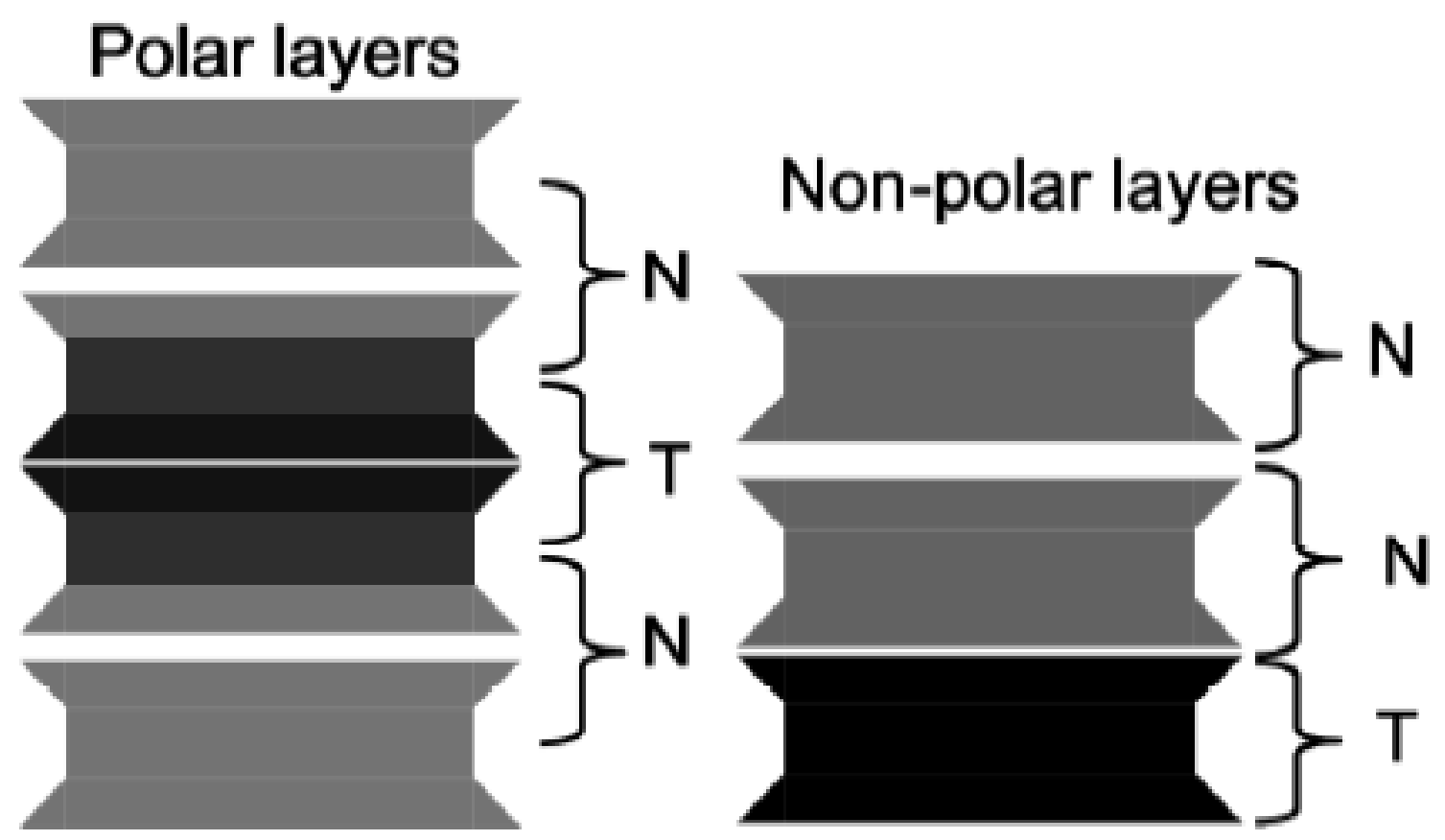


Highlights:

1) Seafloor hydrothermal clays are mainly mixed-layer Mg-and Fe-rich phases.

2) Non-expandable clay layers trap molecular water near to structural Fe.

3) Water in Fe-, Mg-rich clay on Mars may not necessarily indicate smectite.

4) Octahedral sheets in clay layers have domains of different composition.

5) Clay layers are polar and do not correspond to mineral end-members. 